\title{
The Use of Metal Filled Via Holes for Improving Isolation in LTCC RF and Wireless Multichip Packages
}

\author{
George E. Ponchak, Donghoon Chun, Jong- Gwan Yook, Linda P. B. Katehi
}

\begin{abstract}
LTCC MCMs for RF and wireless systems often use metal filled via holes to improve isolation between the stripline and microstrip interconnects. In this paper, results from a 3D-FEM electromagnetic characterization of microstrip and stripline interconnects with metal filled via fences for isolation are presented. It is shown that placement of a via hole fence closer than three times the substrate height to the transmission lines increases radiation and coupling. Radiation loss and reflections are increased when a short via fence is used in areas suspected of having high radiation. Also, via posts should not be separated by more than three times the substrate height for low radiation loss, coupling, and suppression of higher order modes in a package.
\end{abstract}

Index Terms-microstrip, stripline, coupling, crosstalk, MCM, microwave transmission lines

\section{INTRODUCTION}

$\mathrm{RF}$ and wireless package designs must become smaller to satisfy the demands of the commercial and government markets. Simultaneously, the package must house data processing, biasing, and memory circuits in addition to the RF circuits to reduce the overall system size and complexity. Even more ambitious systems being developed by NASA include microelectromechanical (MEM) gyroscopes, active pixel sensors, and other micromachined scientific instruments with the already mentioned electronic circuits to create entire systems in a package. While the size of the package is being reduced and the complexity increased, the cost must also be reduced. To achieve these utopian goals, many MultiChip Module (MCM) technologies have been proposed [1-5], but Low Temperature Cofired Ceramic (LTCC) may be the ideal packaging technology.

The material used in LTCC packages has a moderate dielectric constant, $4<\varepsilon_{T}<8$, which permits wider microwave transmission lines and thus lower conductor loss than circuits on $\mathrm{Si}, \mathrm{GaAs}$, or Alumina. In addition, it has a low loss tangent of 0.002 at $10 \mathrm{GHz}$, which results in low dielectric attenuation. LTCC packages comprise many 0.1-0.15 mm thick ceramic layers with transmission lines on each layer [2,6]. Vertical interconnects between the layers are easily manufactured by laser or 
mechanical drilling the ceramic when it is in the green state. Therefore, a dense package with RF transmission lines, bias lines, and control lines can be manufactured.

However, the high density of transmission lines increases the potential for coupling or crosstalk. The RF integrated circuits are typically mounted on the surface. Therefore, although most of the RF signal routing is done with stripline, the final connection to the integrated circuits requires microstrip. Microstrip transmission lines radiate at discontinuities [7], and microstrip and stripline couple to neighboring transmission lines [8]. While couplers do make use of this coupling, radiation and coupling usually contribute to spurious resonances and degraded circuit performance. To help alleviate the coupling, metal filled via holes are often used to electrically isolate areas of the package since they are inexpensive to build using LTCC technology [9-11]. In addition, via holes may be constructed into fences through which microstrip or stripline transmission lines pass [12-14]. Thus, an LTCC MCM will appear as shown in Figures 1 and 2. A difficulty facing package designers though is a lack of design rules on the proper placement of the via posts.

In this paper, we utilize a 3D-Finite Element Method (FEM) [15] to evaluate the use of metal filled via hole fences to decrease the coupling between adjacent microstrip lines and adjacent striplines. Novel shielding structures are developed that lower coupling between microstrip lines by $10 \mathrm{~dB}$. Then, design rules are proposed to reduce radiation loss and coupling in LTCC packages. All of the structures analyzed are typical for standard LTCC packages and thus relevant for package designers, but the results are applicable to other multilayer circuit technologies such as MCM-D and MCM-L and surface mount technologies on FR4 and RT/Duroid microwave substrates as well.

\section{MICROSTRIP AND VIA HOLE FENCES}

Figure 3 illustrates a microstrip line surrounded by a fence made of metal filled via holes. All of the microstrip lines analyzed in this paper have a relative substrate permittivity, $\varepsilon_{\mathrm{r}}$, of 5.2 ; a substrate thickness, $h$, of $0.25 \mathrm{~mm}$; a strip width, W, of $0.414 \mathrm{~mm}$ which results in a $50 \Omega$ characteristic impedance; and the via holes are $0.25 \mathrm{~mm}$ in diameter. All of these parameters are standard for production LTCC packages.

Initially, the microstrip lines were characterized over the frequency range of 10 to $40 \mathrm{GHz}$ with the conditions that the metals are perfect electrical conductors and the dielectrics are perfect insulators. Thus, any attenuation that is presented is only due to radiation loss. The scattering parameters do not vary by more than a few percent over this bandwidth if the distance between the via hole fences, $2 S+W$, is less than $\lambda_{d} / 2$ where $\lambda_{d}$ is the wavelength in the dielectric medium and $S$ is the distance between the microstrip and the via post. This condition is necessary to avoid unwanted dielectric filled rectangular waveguide 
type modes to propagate between the two metal fences. Since the S-parameters do not vary greatly with frequency, the characteristics are presented as a function of the geometric parameters to permit design rules to be obtained.

The magnitude of the return and insertion loss, $\left|S_{11}\right|$ and $\left|S_{21}\right|$ respectively, are plotted in Figures $4 \mathrm{a}$ and $4 \mathrm{~b}$ respectively as a function of $S$ and the distance between the via holes, $G$, normalized to the substrate thickness, $h$. Since the conductor and dielectric losses are zero, $1-\left|S_{11}\right|^{2}-\left|S_{21}\right|^{2}$ yields the radiation loss and is also shown on Figure 4a. The radiation loss, $\left|S_{11}\right|$, and $\left|S_{21}\right|$ all degrade as $S / h$ decreases or $G / h$ increases. It is also seen that $S / h>3$ is required for low attenuation and return loss; this agrees with the microstrip design rule of maintaining $3 \mathrm{~h}$ separation between components [16]. As a basis of comparison, the radiation loss, $\left|S_{11}\right|$, and $\left|S_{21}\right|$ for an isolated microstrip line at $25 \mathrm{GHz}$ are calculated using the FEM to be $-12 \mathrm{~dB},-35 \mathrm{~dB}$, and $-0.3 \mathrm{~dB}$ respectively. Therefore, a metal fence changes the microstrip line characteristic impedance and thus increases the return loss. (Throughout this paper, the line widths are not changed to maintain $50 \mathrm{Ohm}$ characteristic impedance as the via fences are introduced.) More importantly, a via fence with $S / h>3$ decreases the radiation loss by approximately $3 \mathrm{~dB}$.

The calculated effective permittivity is determined from the guided wavelength, $\lambda_{B}$, of the microstrip mode and the free space wavelength, $\lambda_{0}, \varepsilon_{\mathrm{eff}}=\left(\lambda_{0} / \lambda_{\mathrm{g}}\right)^{2}$, and is shown in Figure 5 . Again, it is seen that when the via fence is greater than $3 \mathrm{~h}$ away from the microstrip line, $S / h>3$, the propagation constant of the fence surrounded microstrip is similar to the isolated microstrip. Notice that $\varepsilon_{\text {eff }}$ is lower when the via fence is near the microstrip line indicating that the electric fields are terminating on the top of the metal via posts instead of on the ground plane. Using standard Transverse Electromagnetic (TEM) transmission line analysis, decreasing $\varepsilon_{\mathrm{eff}}$ as the metal via fence is brought closer to the microstrip line indicates increasing characteristic impedance. This is confirmed by the sign of the calculated return loss in the FEM analysis. Figures $6 a$ and $6 \mathrm{~b}$ show the top view of the magnitude of the electric fields for microstrip lines with $S / h=1$ and $G / h$ of 6 and 1.6 respectively. Even for a very small via post spacing of $G / h=1.6$ or $G=\lambda_{g} / 9$ where $\lambda_{b}$ is the wavelength of the microstrip mode, there are significant fields outside of the via fence. It is these fields that give rise to radiation attenuation.

In all of the field plots shown in this paper, the amount of radiation can be roughly quantified by noting the extent of light blue, green, and yellow away from the microstrip lines. Dark blue is used to indicate regions with no electric fields, or zero fields within the accuracy of the FEM analysis. Therefore, in Figure 6a, it is seen that the fields are approximately $30 \mathrm{~dB}$ lower immediately outside the via fence and $60 \mathrm{~dB}$ lower at $\mathrm{S} / \mathrm{h}=6$ away from the strip than on the strip itself.

Noticing that radiation loss decreases as the via posts are placed closer together, the lowest radiation loss should be obtained by creating a solid metal wall. However, LTCC package manufacturing does not permit this. An alternative approach proposed here is to use a metal strip to connect the tops of every via post in the fence as shown in Figure 7 . The radiation loss, return loss, and insertion loss for this new structure is shown in Figures $4 \mathrm{a}$ and $4 \mathrm{~b}$ where it is seen that the additional strip 
provides $3 \mathrm{~dB}$ reduction in radiation loss and lower return loss compared to the simple via fence. Figure 8 , which shows the electric field for the microstrip lines shown in Figures 3a and 7, illustrates that the reduction in radiation loss is due to better field confinement in the substrate and in the air immediately above the microstrip line. It must be noted that the connecting strip used in this paper is the same width as the via hole diameter. Therefore, the propagating mode is a hybrid microstrip/finite ground coplanar waveguide [17] mode and the surface of the substrate is still available for other interconnects and integrated circuits. This is different from the connecting strips used in [12] that result in CPW modes and utilizes the entire surface of the substrate.

While attenuation degrades circuit efficiency, radiation also leads to coupling or crosstalk, which often leads to severe circuit performance degradation. Coupling between two parallel microstrip lines of approximately $11.7 \mathrm{~mm}$ in length on opposite sides of a via fence as shown in Figure 9 is evaluated using the 3D-FEM. Port 1 is excited with the microstrip mode and the magnitude of the resulting electric field is determined at the other ports. Figure 10a shows a top view of the electric field distribution for the case of $\mathrm{S} / \mathrm{h}=3$ and $\mathrm{G} / \mathrm{h}=1.6$. Clearly visible as dark spots between the two microstrip lines are the via posts. Furthermore, the strong coupling, especially in the forward direction $\left(\mathrm{S}_{41}\right)$, is easily seen. The magnitude of the electric fields for the same structure as in Figure 10a but with a strip connecting the via posts is shown in Figure 10b. Lower coupling in both the forward and backward directions is clearly seen. A similar structure without a via is also evaluated. Forward coupling for each of the three structures is shown in Figure 11. It is interesting to note that the via fence without the connecting strip provides no reduction in coupling compared to two parallel microstrip lines, and in fact, the coupling is increased by 1-2 $\mathrm{dB}$ over most of the frequency range. However, the addition of the connecting strip reduces the coupling by an average of $8 \mathrm{~dB}$ and a maximum of $10 \mathrm{~dB}$. These observations agree with the results for radiation loss of microstrip lines shown in Figure 4. Figure 11 also shows that while wide via posts spacing, large $\mathrm{G} / \mathrm{h}$, may be used below $20 \mathrm{GHz}$, a minimum via spacing of 3.2 is required for low coupling through $40 \mathrm{GHz}$.

In LTCC packages, short via fences around areas that are suspected of having high radiation such as vertical interconnects and highly reflective terminations are often used [9-11]. The use of these localized fences is investigated by characterizing a six-post fence with $\mathrm{G} / \mathrm{h}=1.6$ on both sides of a long microstrip line as shown in Figure 12 . The magnitude of the electric fields for this figure are shown in Figure 13 where the field disturbance created by the localized via fence is seen. The radiation loss, $\left|S_{11}\right|$, and $\left|S_{21}\right|$ for this structure are shown in Figure 14. As with the continuous via fence, $S / h>3$ is required for optimum characteristics. However, through comparison with Figure 4, it is seen that the radiation loss is 3-5 dB higher for the localized via fence while $\left|S_{11}\right|$ for the two cases has similar values. 
Hence, if coupling problems are suspected in microstrip circuits, a continuous via fence connected on the top by metal strip should be used. Furthermore, transmission characteristics are improved if the via holes are placed as close together as possible, and the via fence should be separated from the microstrip line by at least three times the substrate thickness. When coupling does occur, it will be approximately $8 \mathrm{~dB}$ stronger in the forward direction compared to the backward wave coupling.

\section{STRIPLINE AND VIA Hole FENCES}

Stripline surrounded by a via hole fence is illustrated in Figure 15. The ground plane separation, $\mathrm{H}$, is $0.50 \mathrm{~mm}$, the strip width is $0.19 \mathrm{~mm}$, and all of the other parameters have the same value as for the microstrip case. Similar to the characterization of the microstrip lines, the stripline cases do not have a strong frequency dependence if $2 S+W<\lambda_{d} / 2$, and this again permits the results to be plotted as a function of the geometric parameters and not frequency.

Radiation loss, $\left|S_{11}\right|$, and $\left|S_{21}\right|$ as a function of $S / h$ and $G / h$ are plotted in Figure 16. Similar to the microstrip results, all three parameters degrade when the via fence is too close to the stripline, $S / \mathrm{h}<2$, and the characteristics improve if the via posts are closer together. However, the degradation in characteristics for small $\mathrm{S} / \mathrm{h}$ values is not as great for stripline compared to microstrip. Upon further comparison to microstrip, it is also noted that the radiation loss of stripline is approximately $5 \mathrm{~dB}$ lower than for microstrip. The field distribution of the two striplines at $25 \mathrm{GHz}$ with $\mathrm{S} / \mathrm{h}=1$ and $\mathrm{G} / \mathrm{h}=5.2$ and 1.3 are shown in Figures $17 \mathrm{a}$ and $17 \mathrm{~b}$ respectively. While there are strong electromagnetic fields outside the via fence when the via posts are widely separated, closely spaced via posts appear to completely confine the fields. This is different then the microstrip case shown in Figure $6 \mathrm{~b}$ where fields could extend over the fence through the air.

Localized via fences of six posts on both sides of the stripline are also characterized. The characteristics of a stripline with $\mathrm{G} / \mathrm{h}=1.3$ as a function of $S / \mathrm{h}$ are shown on Figure 16. With respect to $S / \mathrm{h}$, the characteristics vary in the same way as they do for the continuous via fence, but the radiation loss is at least $5 \mathrm{~dB}$ higher and $\left|\mathrm{S}_{11}\right|$ is as much as $8 \mathrm{~dB}$ greater for the localized fence. Figure 18 shows the top view of the electric field distribution for the stripline at $25 \mathrm{GHz}$ with $\mathrm{S} / \mathrm{h}=1$ and $\mathrm{G} / \mathrm{h}=1.3$. The higher radiation loss and reflection is seen to be caused by a large perturbation in the electric fields that normally extend outwards from and parallel to the strip when the field encounters the via posts.

Radiation from parallel striplines such as shown in Figure 19 also leads to coupling. Forward coupling, $\mathrm{S}_{41}$, between two $13 \mathrm{~mm}$ long, $50 \Omega$ striplines separated by a via fence with $S / h=1$ and $G / h=1.3$ and between two striplines with no via fence is shown in Figure 20. Across the frequency band of 10 to $40 \mathrm{GHz}$, the coupling is reduced by an average of $10 \mathrm{~dB}$ when a via fence is used. Thus, it is seen that via fences are useful for reducing coupling between striplines, but they are not useful for reducing coupling between microstrip lines unless a strip connects the metal posts. 
Based on these results for stripline, a continuous via fence placed at least $2 \mathrm{~h}$ away from the strip reduces radiation, and via fences reduce coupling between parallel striplines by $10 \mathrm{~dB}$. However, short via fences placed along a stripline increases reflections and radiation loss. Radiation loss and coupling are both reduced as the separation between via posts is reduced.

\section{VIA FENCE PARTITIONS}

As shown in Figure 1, a typical MCM is typically partitioned into smaller compartments to reduce coupling between circuits. An open ended transmission line is known to radiate and therefore is a perfect test circuit to evaluate the use of via fences to partition a cavity. Figure 21 shows a schematic of two open-ended striplines that is characterized. The striplines are separated by a distance of $2 S+D_{v}=3 \mathrm{~h}$ where $D_{v}$ is the via hole diameter, the distance between open ends is $7.2 \mathrm{~mm}$, and all other parameters are the same as described earlier. The characterization is performed over a wide frequency band so that the package supports higher order modes when no metal filled via posts are present. Initially, the circuit is characterized for the case with no via holes. As expected, there is less than $70 \mathrm{~dB}$ of coupling between the two striplines at low frequencies, but when the frequency, $f$, is greater than the cutoff frequency of the $T E_{10}$ rectangular waveguide mode, $f_{c}{ }^{T E_{10}}$, coupling increases to nearly 3 $\mathrm{dB}$ as shown in Figure 22a. Figure $22 \mathrm{~b}$ shows that a single role of via posts can be effective in suppressing higher order modes and reducing coupling above $\mathrm{f}_{\mathrm{c}}^{\mathrm{TE}}{ }_{10}$, but the via fence provides little or no reduction in coupling below $\mathrm{f}_{\mathrm{c}}{ }^{\mathrm{TE}}{ }_{10}$. For coupling below $80 \mathrm{~dB}$ from $0.7<f / \mathrm{f}_{\mathrm{c}} \mathrm{TB}_{10}<1.7, \mathrm{G} / \mathrm{h}<4$ or $\mathrm{G}<\lambda / 4$ is required. Note that the two striplines are not adjacent to each other here as they are in Figure 19; thus, the coupling presented in Figures 22a and 22b is strictly due to radiation from the open ended stripline and not due to the proximity coupling presented in earlier sections.

Discontinuities that radiate less are found to require fewer via holes. Figure 23 shows an illustration of a stripline bending and passing through a continuous via fence from one section of an MCM to another section. Using the same parameters as for earlier cases, the structure is analyzed as a function of frequency and G/h. Figure 24 shows the insertion and reflection loss for this structure as a function of normalized frequency and via hole placement. Again, it is seen that if no via posts are used or if the via posts are too widely spaced, the transmission line characteristics are severely degraded above the cutoff frequency of the packages $\mathrm{TE}_{10}$ mode. However, if $\mathrm{G} / \mathrm{h}<6.2$, there is no degradation in the line characteristics, and satisfactory characteristics are obtained for $G / h=27.8$. Figure 25 more clearly illustrates this. Note the strong $\mathrm{TE}_{10}$ rectangular waveguide mode in Figure 25a; whereas in Figure 25b, only the strip line mode is present.

Although an MCM package may be partitioned by using a via fence with wide post spacing if the circuit is designed with well behaved components, not all circuits can avoid components known to radiate such as open circuit terminated stubs, 
short circuit terminations, and vertical interconnects. Therefore, via fences used for partitions should have a post spacing of less than $4 h$.

\section{CONCLUSIONS}

The use of metal filled via holes in LTCC packages has been characterized. It has been shown that coupling between microstrip lines is not reduced by a simple via fence, but by adding a metal strip to connect the tops of each post, the coupling is reduced by $8 \mathrm{~dB}$. Coupling between two striplines is reduced by $10 \mathrm{~dB}$ when a continuous via fence is used and is approximately $15 \mathrm{~dB}$ lower than for two microstrip lines with a via fence and connecting strip. Therefore, stripline is a better transmission line for multilayer package interconnects. For both transmission lines, short via fences increases radiation loss and reflections by perturbing the propagating mode. Therefore, only continuous via fences should be used. When via fences are used, they should be placed three times the substrate height apart from the strip and the posts should be placed as close together as possible. A maximum post spacing of three times the substrate height is recommended.

The results of this paper demonstrate methods that may be used by circuit and package designers to lower coupling between adjacent microstrip and stripline circuit elements. Using the via fence structures described in this paper, coupling of 22 $\mathrm{dB}$ and $39 \mathrm{~dB}$ between parallel microstrip lines and between parallel striplines at $10 \mathrm{GHz}$ has been demonstrated respectively. This is a reduction in coupling of $8 \mathrm{~dB}$ and $15 \mathrm{~dB}$ compared to lines without via fences for the microstrip and stripline respectively. While this improvement is important for many circuits, it is not sufficient for separating circuits in a multi-chip package where isolation of more than $80 \mathrm{~dB}$ is often required. Thus, further development is required, possibly by using two roles of via fences parallel to each other or connecting the via fences in stripline circuits together as was presented here for the microstrip lines.

\section{REFERENCES}

[1] R. W. Johnson, R. K. F. Teng, and J. W. Balde eds., Multichip Modules Systems Advantages, Major Constructions, and Material Technologies, New York, NY: IEEE Press, 1991.

[2] R. L. Brown, P. W. Polinski, and A, S. Shaikh, "Manufacturing of microwave modules using low-temperature cofired ceramics," in 1994 IEEE MTT-S Int. Microwave Symp. Dig., 1994, pp. 1727-1730.

[3] H. Sakai, Y. Ota, K. Inoue, T. Yoshida, K. Takahashi, S. Fujita, and M. Sagawa, "A novel millimeter-wave IC on Si substrate using flip-chip bonding technology," in 1994 IEEE MTT-S Int. Microwave Symp. Dig., 1994, pp. 1763-1766. 
[4] G. White, E. Perfecto, D. McHerron, T. DeMercurio, T. Redmond, and M. Norcott, "Large format fabrication-a practical approach to low cost MCM-D," IEEE Trans. on Components, Packaging, and Manufacturing Tech.-Part B, Vol. 18, No. 1, pp. 37-41, Feb. 1995.

[5] R. A. Fillion, R. J. Wojnarowski, T. B. Gorcyzca, E. J. Wildi, and H. S. Cole, "Development of a plastic encapsulated multichip technology for high volume, low cost commercial electronics," IEEE Trans. on Components, Packaging, and Manufacturing Tech.-Part B, Vol. 18, No. 1, pp. 59-65, Feb. 1995.

[6] R. W. Johnson, ed., Modular Series in Hybrid Microelectronics, Reston, VA: International Society for Hybrid Microelectronics, 1991.

[7] N. G. Alexopoulos and S. -C. Wu, "Frequency-independent equivalent circuit model for microstrip open-end and gap discontinuities," IEEE Trans. Microwave Theory Tech., Vol. 42, No. 7, pp. 1268-1272, July 1994.

[8] R. E. Collin, Foundations for Microwave Engineering, pp. 164-175, New York, NY: McGraw-Hill, Inc., 1992.

[9] J. W. Gipprich, "EM modeling of via wall structures for high isolation stripline," in Digest for Workshop WWFC, Interconnect and Packaging Technologies and Issues, IEEE Int. Microwave Symp., San Diego, CA, pp. 78-114, June 1994.

[10] J. Gipprich, C. Wilson, and D. Stevens, "Multilayered 3-D packaging issues," in Digest for Workshop WFC, Interconnects and Packaging for RF Wireless Communications Systems, IEEE Int. Microwave Symp., Denver, CO, June 8-13, 1997.

[11]J. Gipprich and D. Stevens, "Isolation characteristics of via structures in high density stripline packages," in Digest for Workshop WME, Multilayer Microwave Circuits, IEEE Int. Microwave Symp., Baltimore, MD, June 7-12, 1998.

[12]M. - K. Kim, "Crosstalk control for microstrip circuits in PCBs at microwave frequencies," in Proc. of Int. Symp. On Electromagnetic Compatibility, 1995, pp. 459-464.

[13]G. E. Ponchak, D. Chen, J. -G. Yook, and L. P. B. Katehi, "Characterization of plated via hole fences for isolation between stripline circuits in LTCC packages," IEEE MTT-S Int. Microwave Symp. Dig., 1998, pp. 1831-1834.

[14] G. E. Ponchak, D. Chen, J.- G. Yook, and L. P. B. Katehi, "Filled via hole fences for crosstalk control of microstrip lines in LTCC packages," in 3rd International Wireless Communications Conference (WCC '98) Digest, San Diego, CA, Nov. 1-3, 1998, pp. 96-100. Also in Proc. IMAPS 199831 st Int. Symp. on Microelectronics, San Diego, CA, Nov. 2-4, 1998.

[15] J. -G. Yook, N. Dib, and L. Katehi, "Characterization of High Frequency Interconnects using Finite Difference Time Domain and Finite Element Methods," IEEE Trans. Microwave Theory Tech., Vol. 42, No. 9, pp. 1727-1736, Sept. 1994.

[16] R. Goyal, Monolithic Microwave Integrated Circuits: Technology \& Design, Norwood, MA: Artech House, pp., 358-372, 1989. 
[17]G. E. Ponchak and L. P. B. Katehi, "Finite ground coplanar (FGC) waveguide: a better transmission line for microwave circuits," Advancing Microelectronics, Vol. 25, No. 3, pp. 15-18, May/June 1998. 
Footnotes:

Manuscript received; revised. This work was presented in part at the $3 \mathrm{rd}$ International Wireless Communications Conference (WCC '98), San Diego, CA, Nov. 1-3, 1998 and the 1998 IEEE MTT-S Int. Microwave Symp., Baltimore, MD, June 7-12, 1998. This work was supported by NASA Glenn Research Center and the University of Michigan Center for Parallel Computing which is partially funded by NSF grant CDA-92-14296 and Ford Motor Company. George E. Ponchak is with the Electron Device Technology Branch, NASA Glenn Research Center, Cleveland, OH 44135 USA. Donghoon Chun and Linda P. B. Katehi are with the Department of Electrical Engineering and Computer Science, University of Michigan, Ann Arbor, MI 48109-2122, USA. Jong-Gwan Yook is now with the Dept. of Information and Communications, Kwang-Ju Institute of Science and Technology, Kwang-Ju, Book-ku, O-ryongdong, Korea, $500-712$ 
George E. Ponchak received the B. E. E. degree from Cleveland State University in 1983, the M.S.E.E. degree from Case Western Reserve University in 1987, and Ph.D. from the University of Michigan in 1997. In July 1983, he joined the staff of the Communication Technology Division at NASA Lewis Research Center in Cleveland, $\mathrm{OH}$ where he is now a senior research engineer. He is interested in passive circuits, multilayer intercon of microwave and millimeter-wave printed transmission lines and components, and microwave packaging, uniplanar circuits, microwave microelectromechanical (MEMS) InP and SiGe MMIC development $\mathrm{GaAs}$ and SiGe referred journals and symposia proceedings. Dr. Ponchak was and co-author of more than 50 papers in University in Cleveland, OH for the 1997/1998 school year. Dr Ponchak is a senior member of the lear.

Microel Dr. Ponchak is a senior member of the IEEE MTT-S and a member of the International Microelectronics and Packaging Society (IMAPS). He received the Best Paper of the ISHM'97 30 th
International Symposium on Microelectronics Award. 
Donghoon Chun was born in Korea. He received the B.S and M.S. degrees in Electronics Engineering from Dong-A University, Pusan, Korea, in 1988 and 1992,respectively. He continued his study in the University of Michigan at Ann Arbor in Electrical Engineering and Computer Science (EECS) in 1994 and received his 2nd M.S. degree in 1996. He is currently working toward the Ph.D. degree in the same department.

He is a Research Assistant in the University of Michigan's Radiation Laboratory. His research interests are the electromagnetic characterization of microwave monolithic integrated circuits (MMICs) using the hybrid finite-element-method (FEM)/method-of-moment (MoM) with emphasis on parallel computing. 
Jong-Gwan Yook (S'86, M'97) was born in Korea. He received the BS and MS degrees in Electronics the University of Michigan, Ann Arbor, Michigan, in 1996.

Currently he is an Assistant Professor at the Kwang-Ju Institute of Science and Technology (K-JIST),
Korea. His main research interests are in characterization of microwave/millimeter-wave of theoretical/numerical electromagnetic modeling and and RF MEMS devices using frequency and time domain foll numerical techniques for analysis and design of high-speed high-frequenods, and development of parallel/super computing and wireless communication applications. 
She received the B.S.E.E. degree from the National Technical University of Athens, Greece, in 1977 and the M.S.E.E. and Ph.D. degrees from the University of California, Los Angeles, in 1981 and 1984 respectively. In September 1984 she joined the faculty of the EECS Department of the University of Michigan, Ann Arbor, where she is currently an Associate Dean for Graduate Education and a Professor of Electrical Engineering and Computer Science. She has been interested in the development and characterization (theoretical and experimental) of microwave, millimeter printed circuits, the computeraided design of VLSI interconnects, the development and characterization of micromachined circuits for millimeter-wave and submillimeter-wave applications and the development of low-loss lines for Terahertzfrequency applications. She has also been studying theoretically and experimentally various types of uniplanar radiating structures for hybrid and monolithic circuits, as well as monolithic oscillator and mixer designs.

She has been awarded with the IEEE AP-S W. P. King (Best Paper Award for a Young Engineer) in 1984, the IEEE AP-S S. A. Schelkunoff Award (Best Paper Award) in 1985, the NSF Presidential Young Investigator Award and an URSI Young Scientist Fellowship in 1987, the Humboldt Research Award and The University of Michigan Faculty Recognition Award in 1994, the IEEE MTT-S Microwave Prize in 1996 and the 1997 Best Paper Award from the International Society on Microelectronics and Advanced Packaging. She is a Fellow of IEEE, and a member of IEEE AP-S, MTT-S, Sigma XI, Hybrid Microelectronics, URSI Commission D and a member of AP-S ADCOM from 1992 to 1995. Also, Prof. Katehi is an Associate Editor for the IEEE Transactions of the Microwave Theory and Techniques Society. 
1. Illustration of Low Temperature Cofired Figures

2. Cross sectional view of Low Temperature Cofired CraC) microwave MultiChip Module (MCM). (MCM).

3. (a) Schematic of microstrip line cut.

4. Calculated (a) radiation loss and refection loss, $\left|S_{11}\right|$, and (b) insertion loss, $\left|S_{21}\right|$, for microstrip line surrounded by a continuous metal filled via fence both with and without a connecting strip on the top
surface of the vias.

5. Calculated effective dielectric constant of microstrip line surrounded by a continuous via fence.
6. Top view of the electric field distribution of microstrip line surrounded by a continuous via fence at
$25 \mathrm{GHz}, \mathrm{S} / \mathrm{h}=1$, (a) $\mathrm{G} / \mathrm{h}=6$, (b) $\mathrm{G} / \mathrm{h}=1.6$

, (b) $\mathrm{G} / \mathrm{h}=1.6$ on the substrate surface.

8. Cross sectional cut of the electric field distribution of a (a) microstrip line surrounded by a continuous $\mathrm{GHz}$ and $\mathrm{S} / \mathrm{h}=1$.

9. Schematic of two microstrip lines separated by a metal filled via fence.

10. Top view of the electric field distribution of two microstrip lines separa filled via fence, $f=35 \mathrm{GHz}$, (a) $S / h=1, \mathrm{G} / \mathrm{h}=1.6$ microstrip lines separated by a continuous metal

11. Calculated forward coupling, $S_{41}$, between frequency and via posts spacing.

12. Schematic of microstrip line with a short via fence on both sides.

13. Top view of the electric field distribution of microstrip line surrounded by a localized via fence at 25
$\mathrm{GHz}, \mathrm{S} / \mathrm{h}=1, \mathrm{G} / \mathrm{h}=1.6$ 14. Calculated (a) radiation loss and reflection loss, $\left|S_{11}\right|$, and (b) insertion loss, $\left|S_{21}\right|$, for microstrip line
surrounded by a 6-posts metal filled via fence.

15. (a) Schematic of stripline surrounded by a continuous metal filled via fence and (b) cross section.

16. Calculated (a) radiation loss and reflection loss, $\left|S_{11}\right|$, and (b) insertion loss, $\left|S_{21}\right|$, for stripline surrounded by a continuous metal filled via fence and a short, 6-posts, via fence.

17. Top view of the electric field distribution of $\mathrm{GHz}, \mathrm{S} / \mathrm{h}=1$, and (a) $\mathrm{G} / \mathrm{h}=5.2$ and (b) $\mathrm{G} / \mathrm{h}=1.3$.

18. Top view of the electric field distribion $\mathrm{S} / \mathrm{h}=1$, and $\mathrm{G} / \mathrm{h}=1.3$.

19. Schematic of adjacent striplines separated by a metal filled via fence

20. Calculated forward coupling, $S_{41}$, between two parallel striplines with and without a via fence.

21. Schematic of two open ended striplines enclosed in a metal cavity and separated by a via fence.

of via posts.
. Calculated coupling between two open-ended striplines in a metal cavity as a function of the number

23. Schematic of a stripline passing through a continuous metal filled via fence. 24. Calculated insertion and reflection loss of a stripline passing through a continuous metal filled via
fence in a metal cavity as a function of the number of via posts. 25. Top view of the electric field distribution of stripline passing through a continuous metal filled via
fence at $\mathrm{f} / \mathrm{f}_{\mathrm{e}}^{\mathrm{TE}} \quad 10=1.44$, and (a) $\mathrm{G} / \mathrm{h}=56.76$ and (b) $\mathrm{G} / \mathrm{h}=6.2$. 


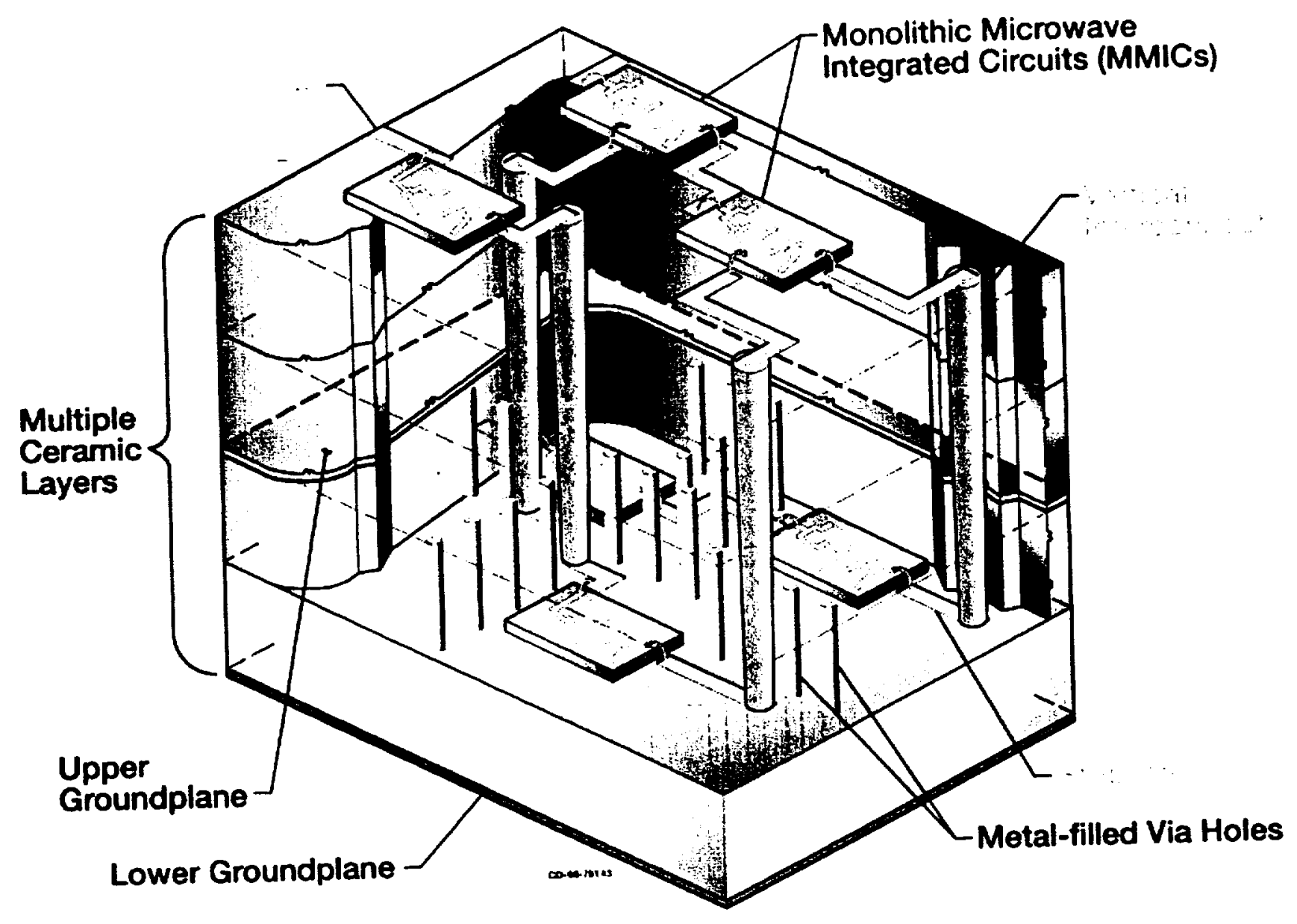

Figl 1 


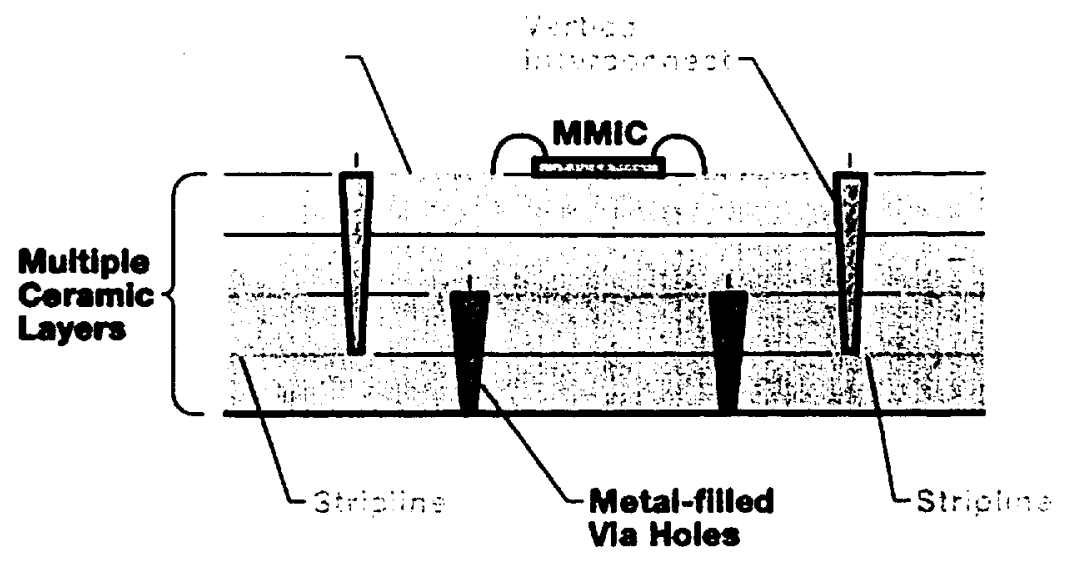

Fig $z$ 


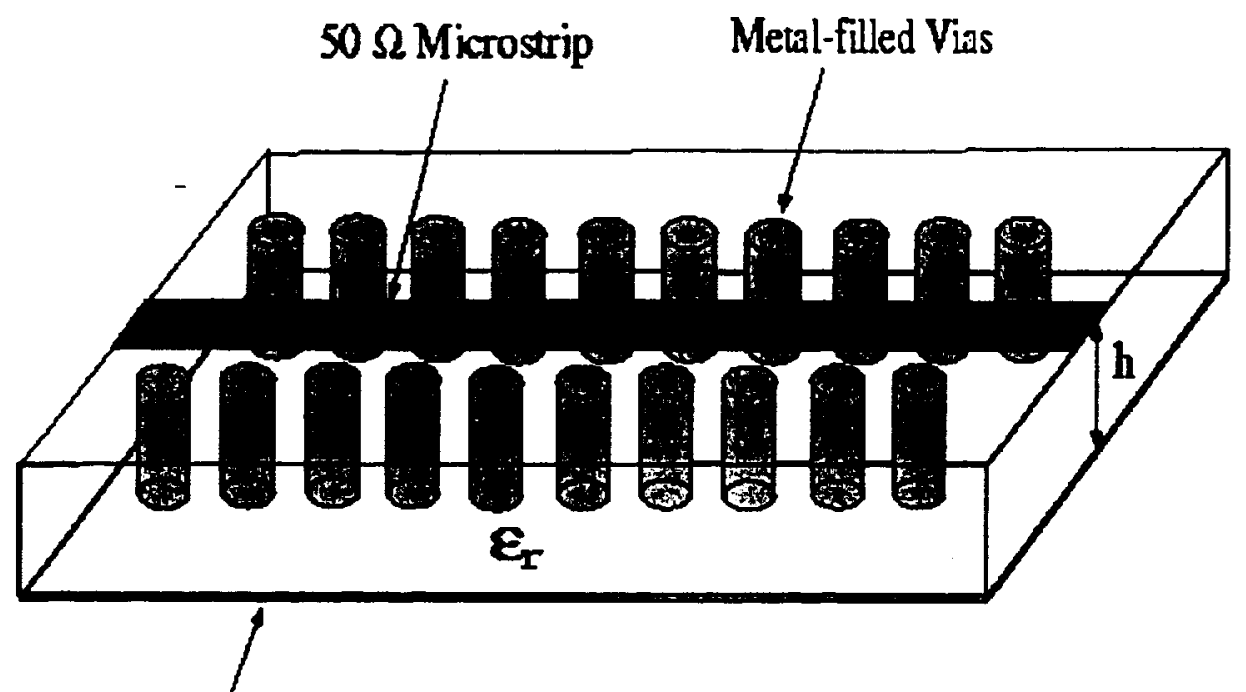

Ground Plane $\quad \varepsilon_{5}=5.2 \quad h=0.25 \mathrm{~mm}$

Fig $3 a$ 


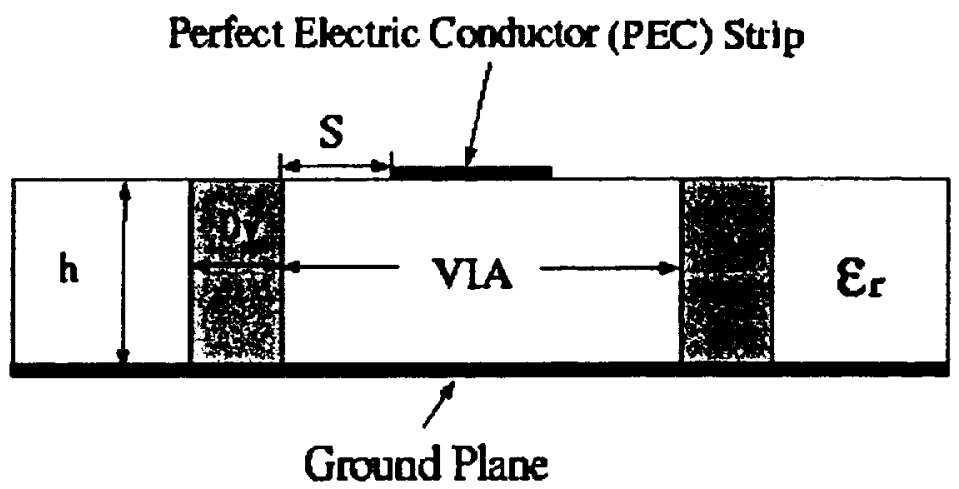

Fig $3 b$ 


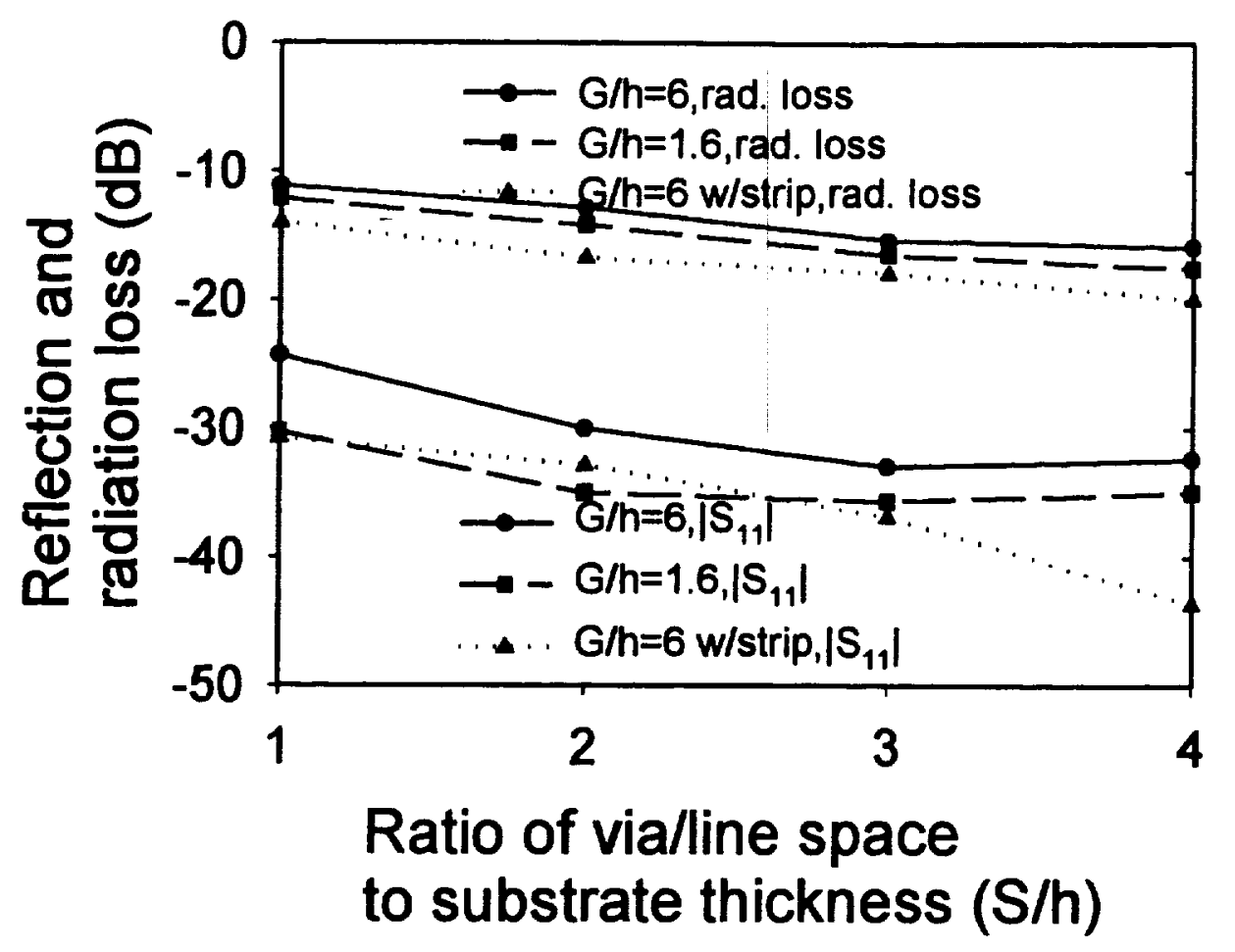

Fig $4 a$ 


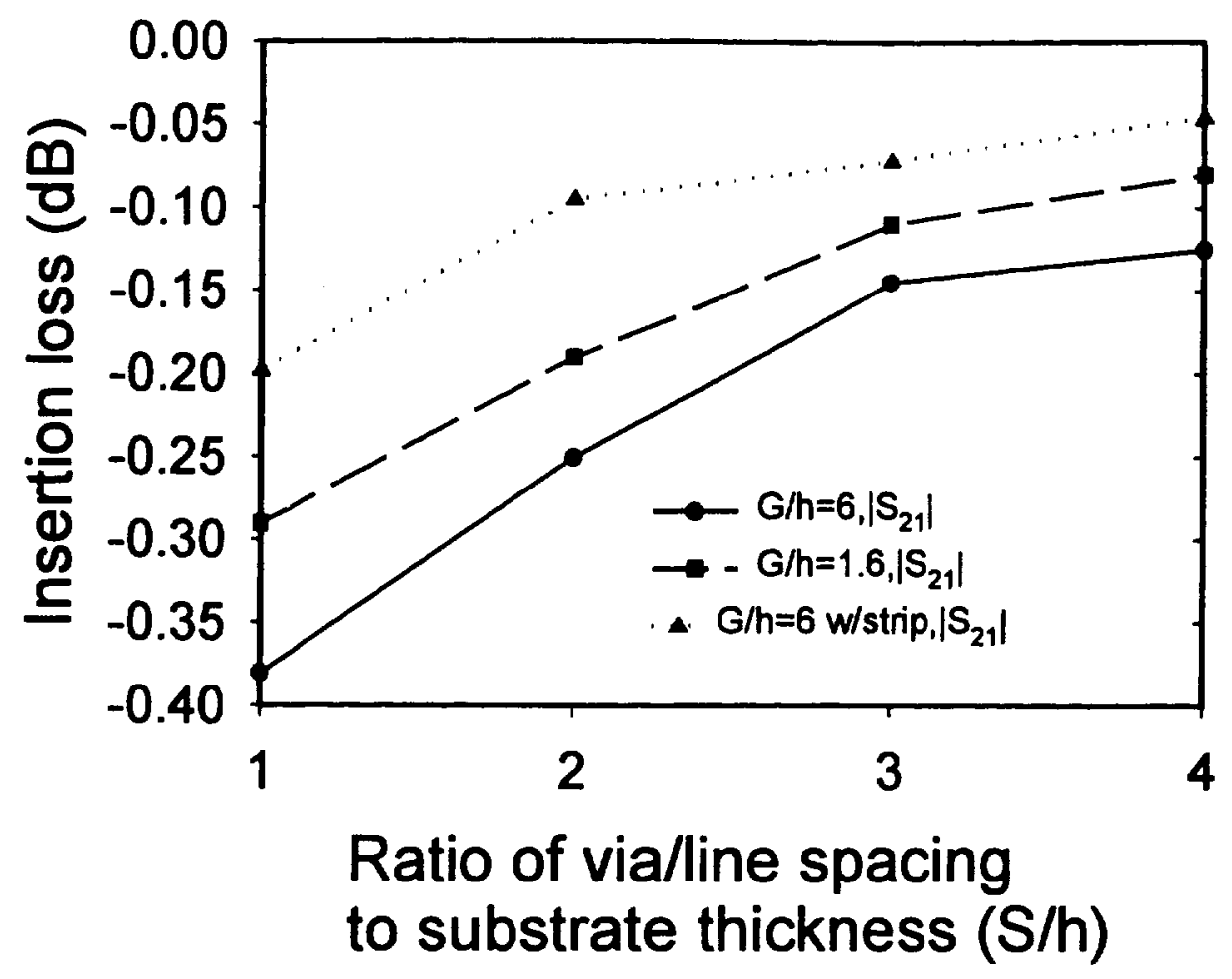

Fig $4 b$ 


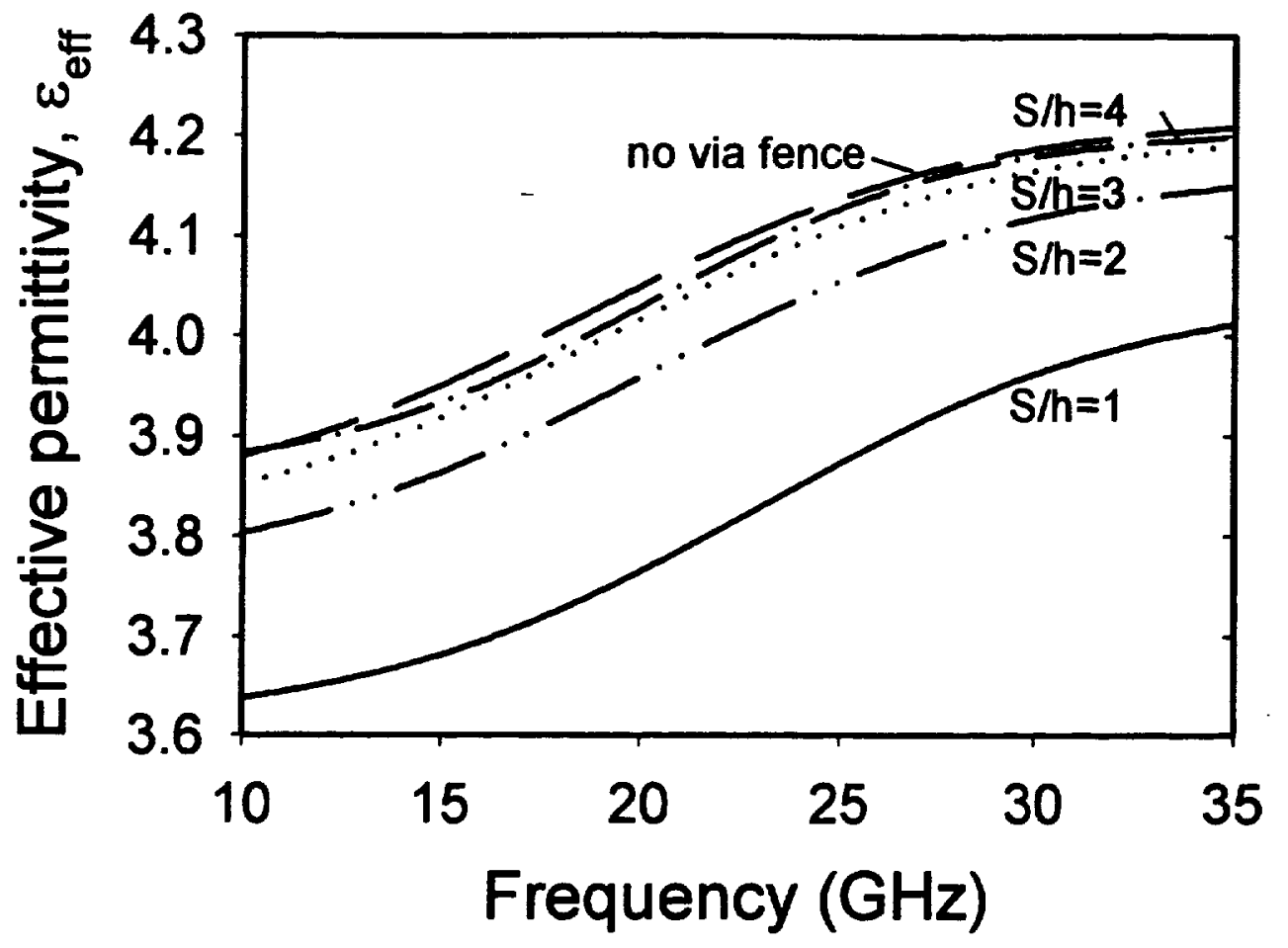

Fig $S$ 
$|\mathrm{E}|^{2},(\mathrm{~dB})$

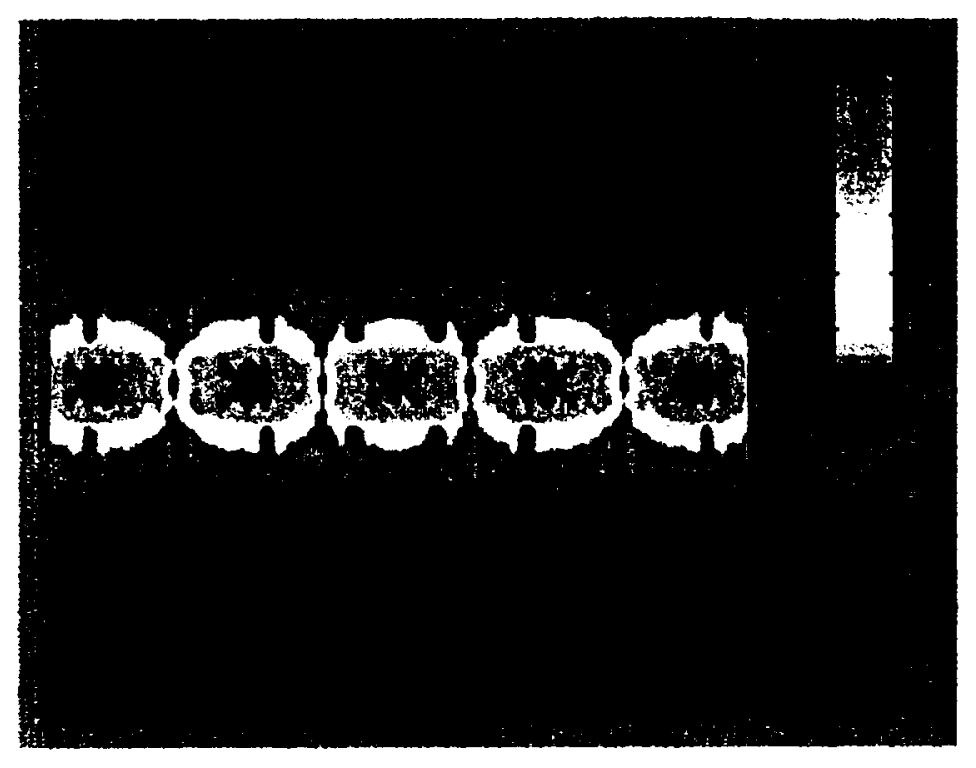

Fig $6 a$ 
$|E|^{2},(d B)$

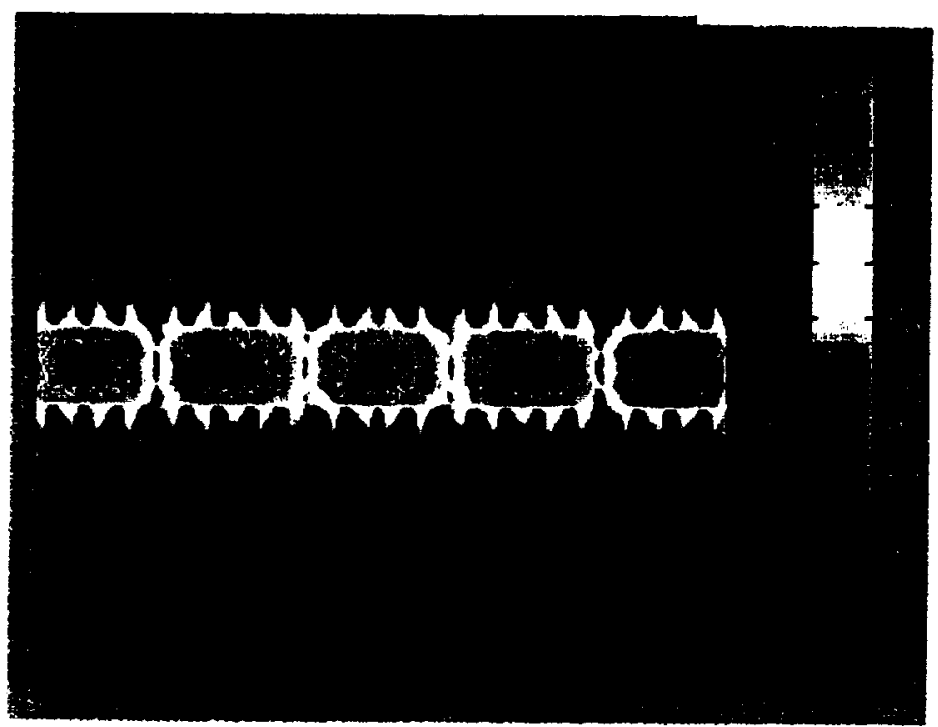

Fig 66 


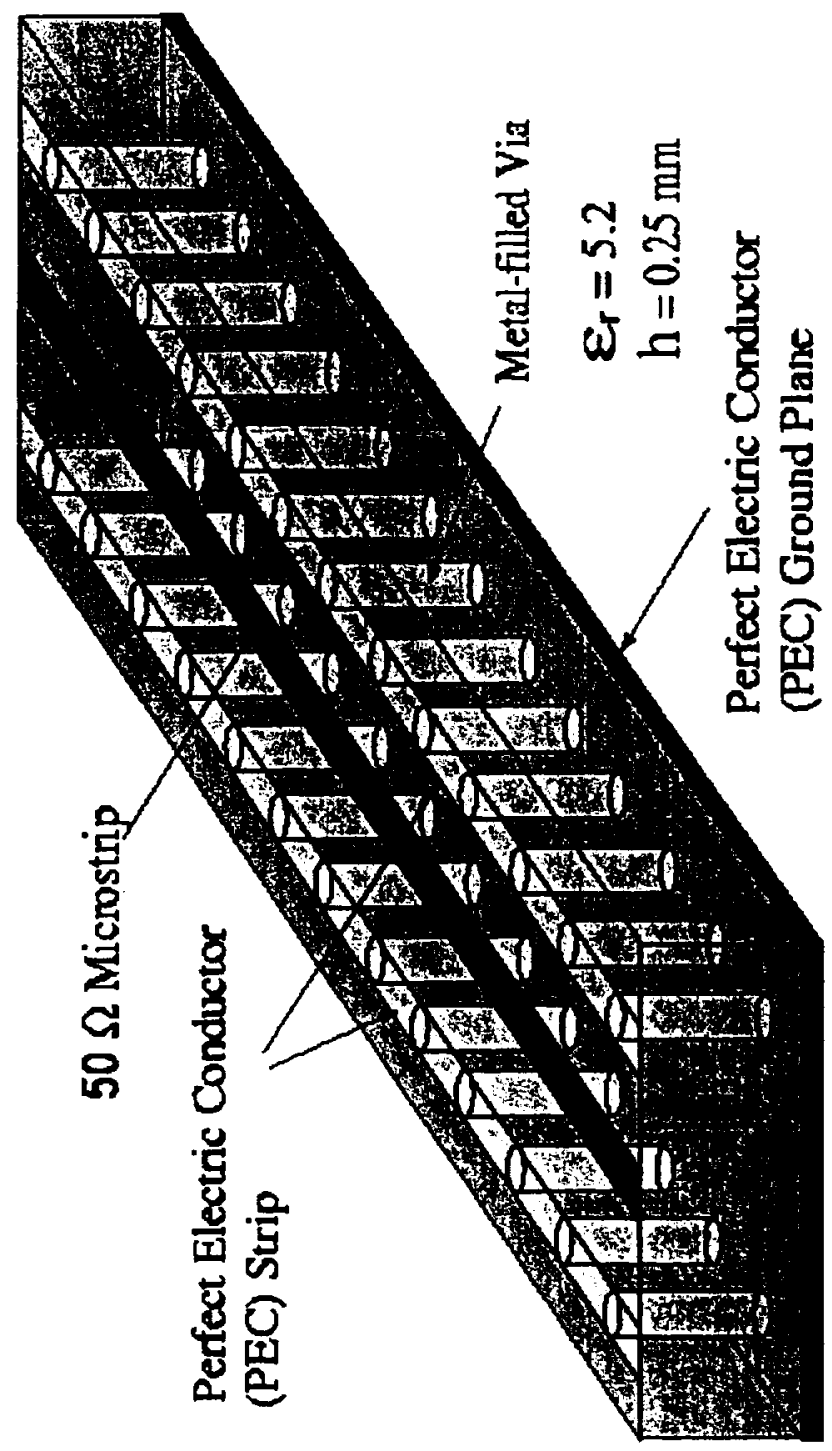


$|\mathrm{E}|^{2},(\mathrm{~dB})$

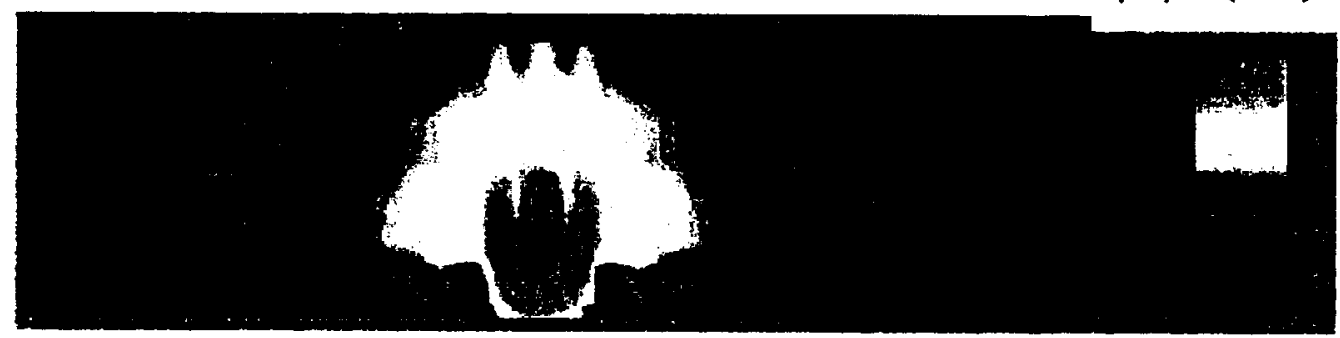

Fig $8 a$ 
$|\mathrm{E}|^{2},(\mathrm{~dB})$

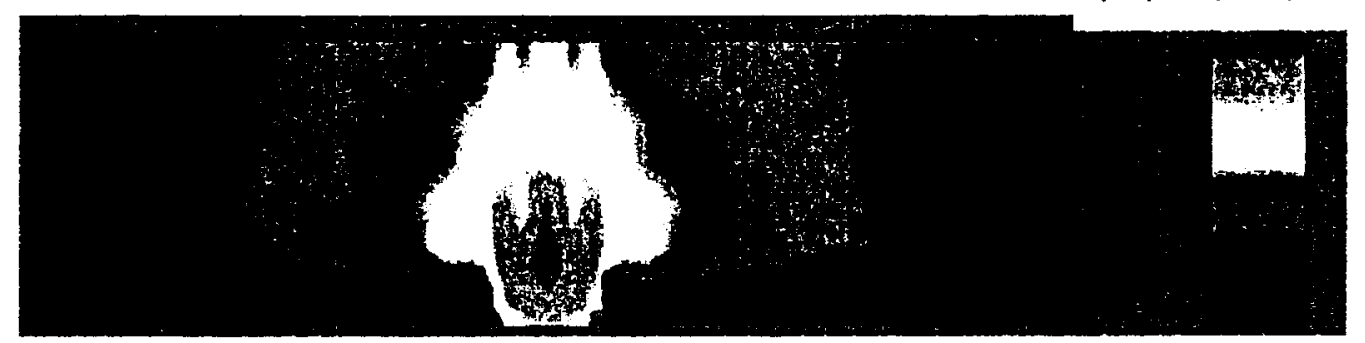

Fig 86 


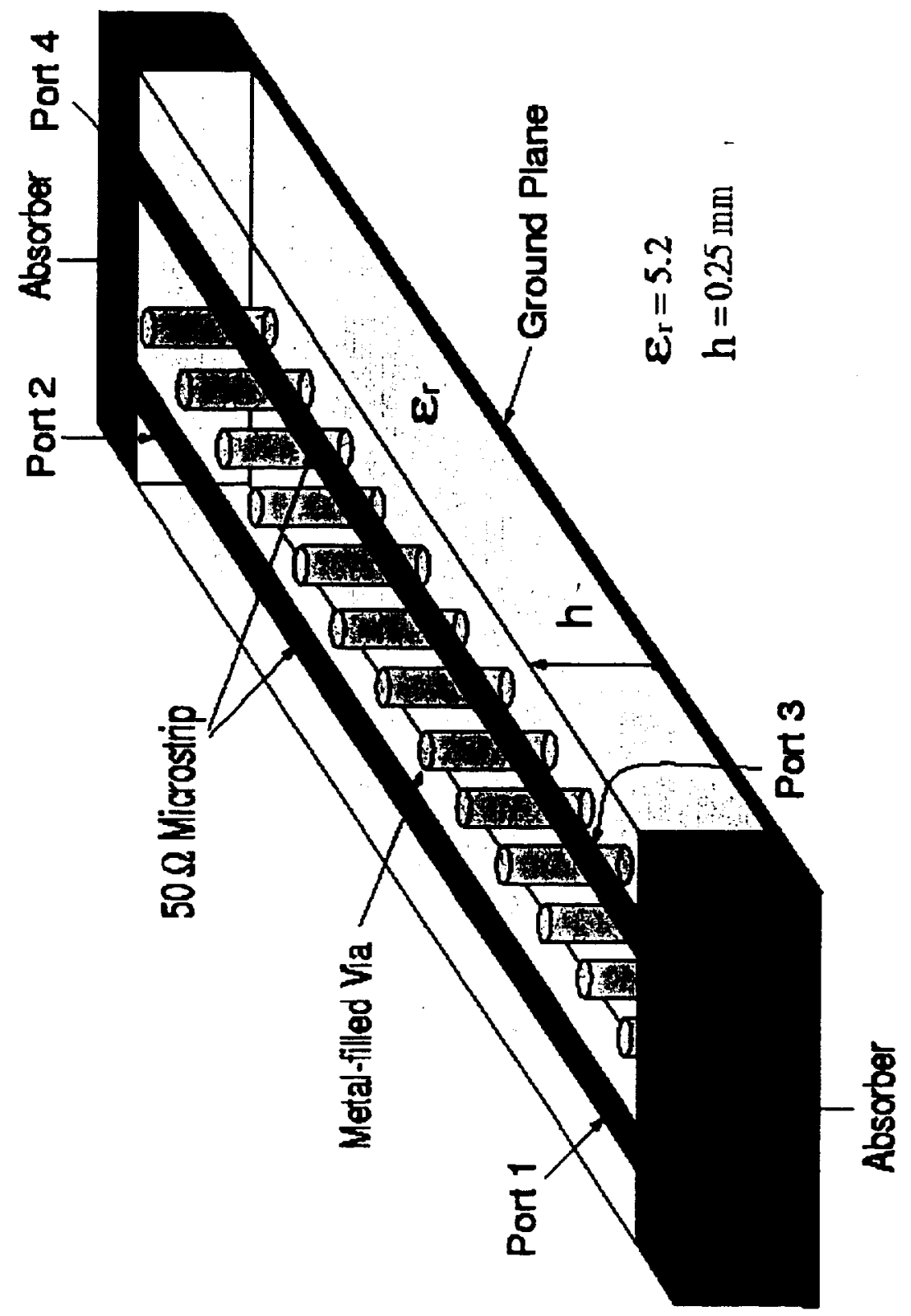




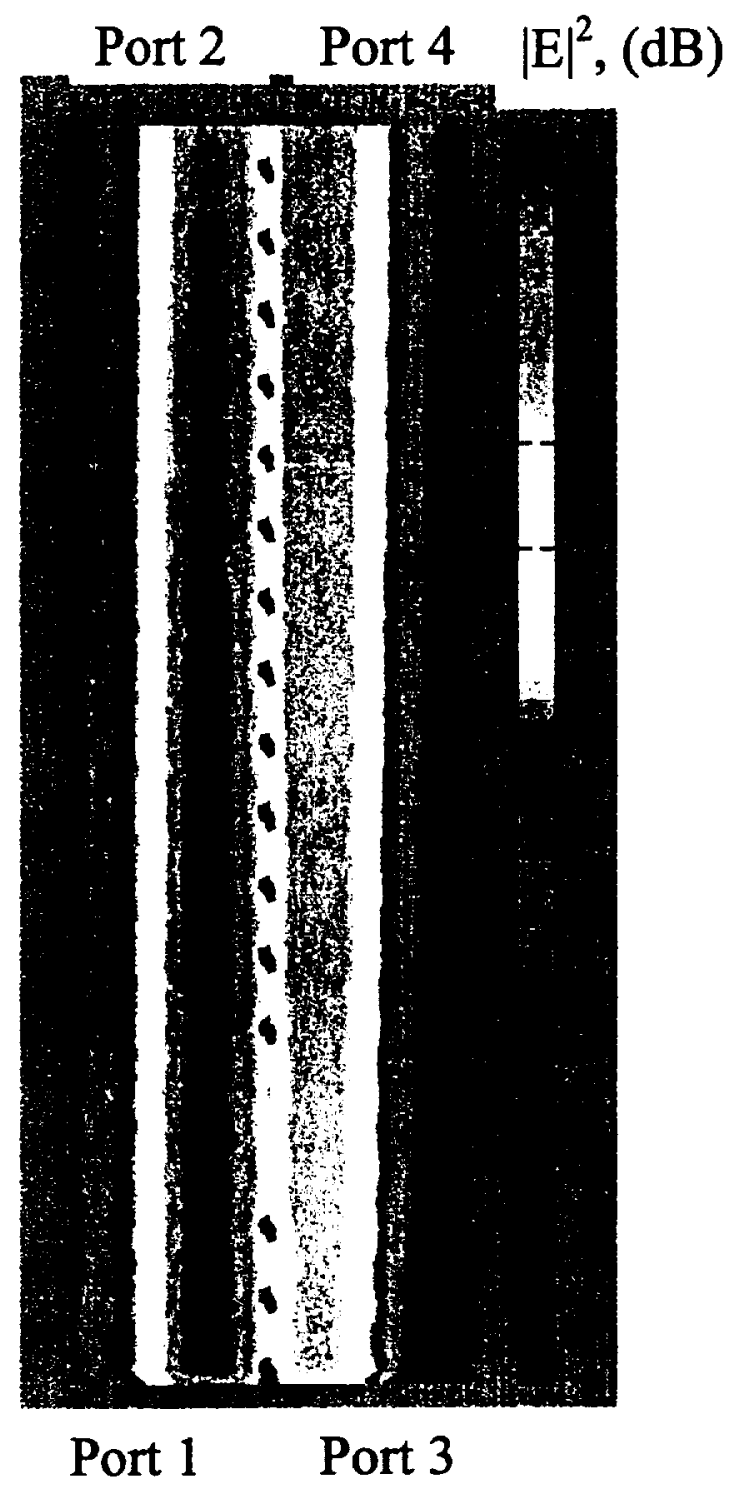

Fig loa 


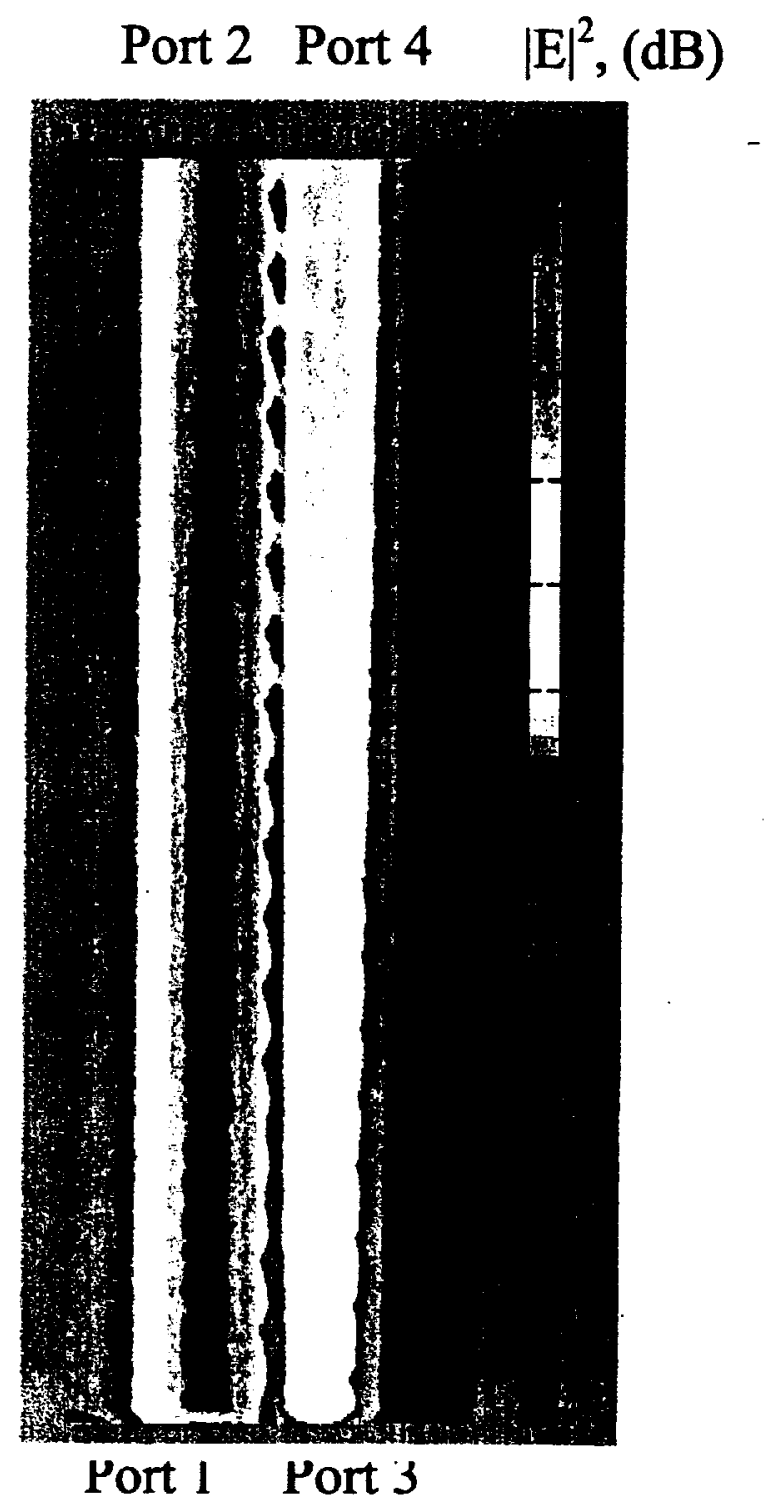

Fig $10 b$ 


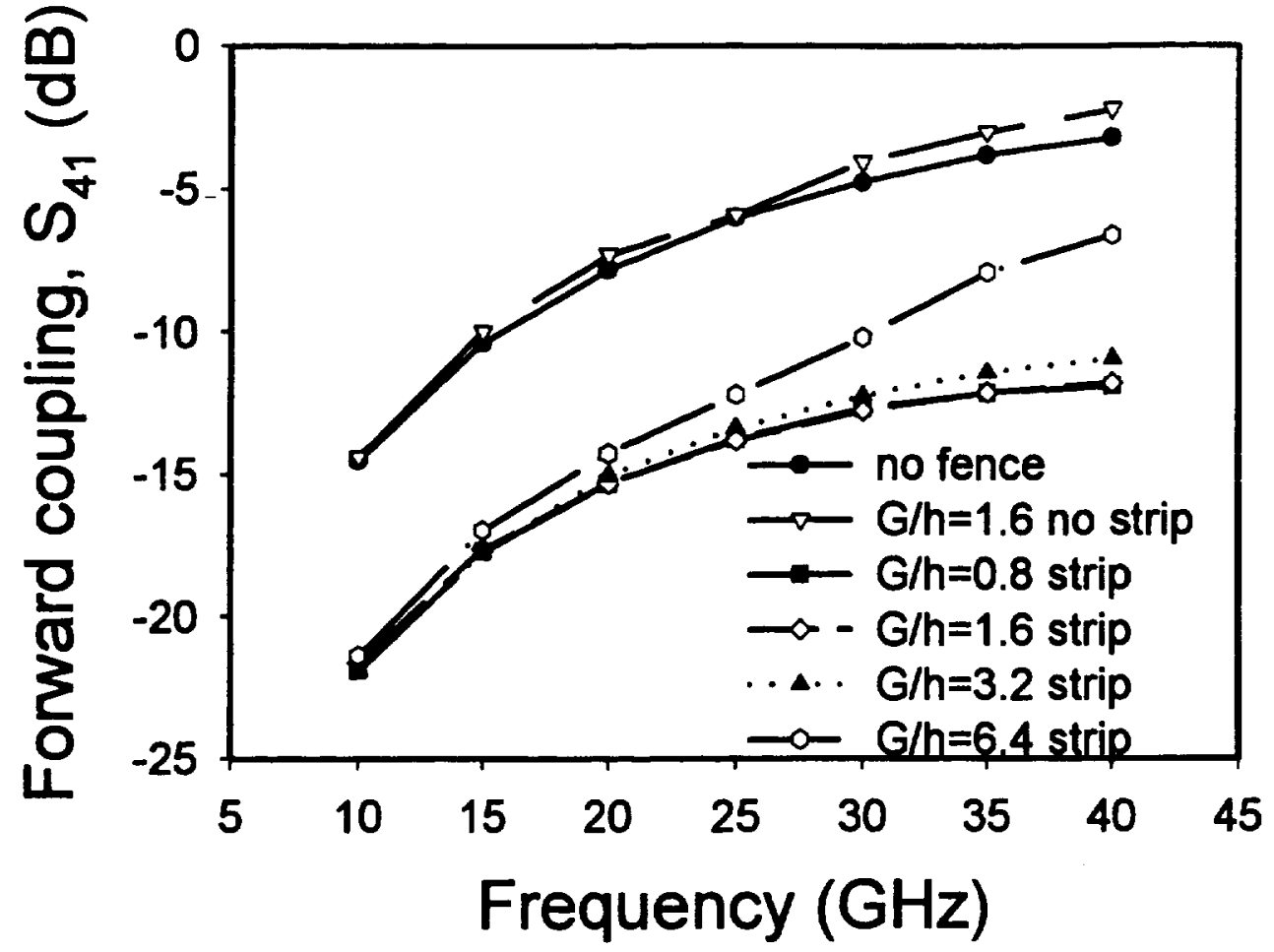

Fig 11 


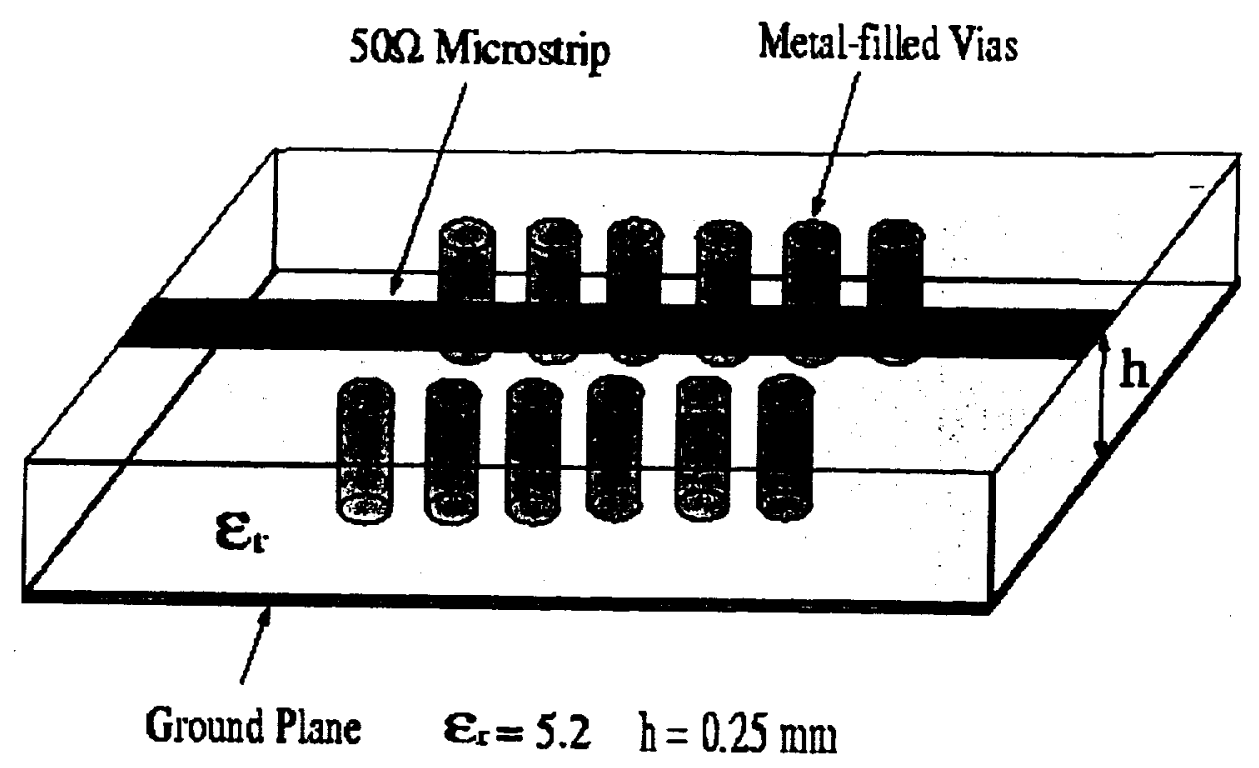

$F_{1 g} 12$ 
$|\mathrm{E}|^{2},(\mathrm{~dB})$

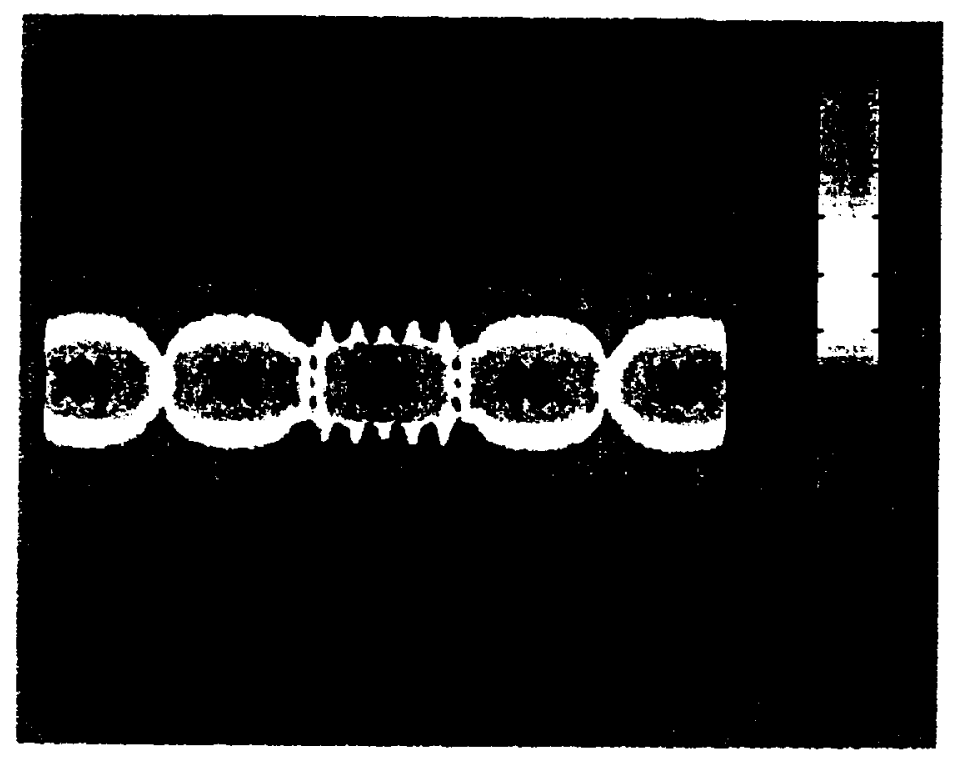

Fig 13 


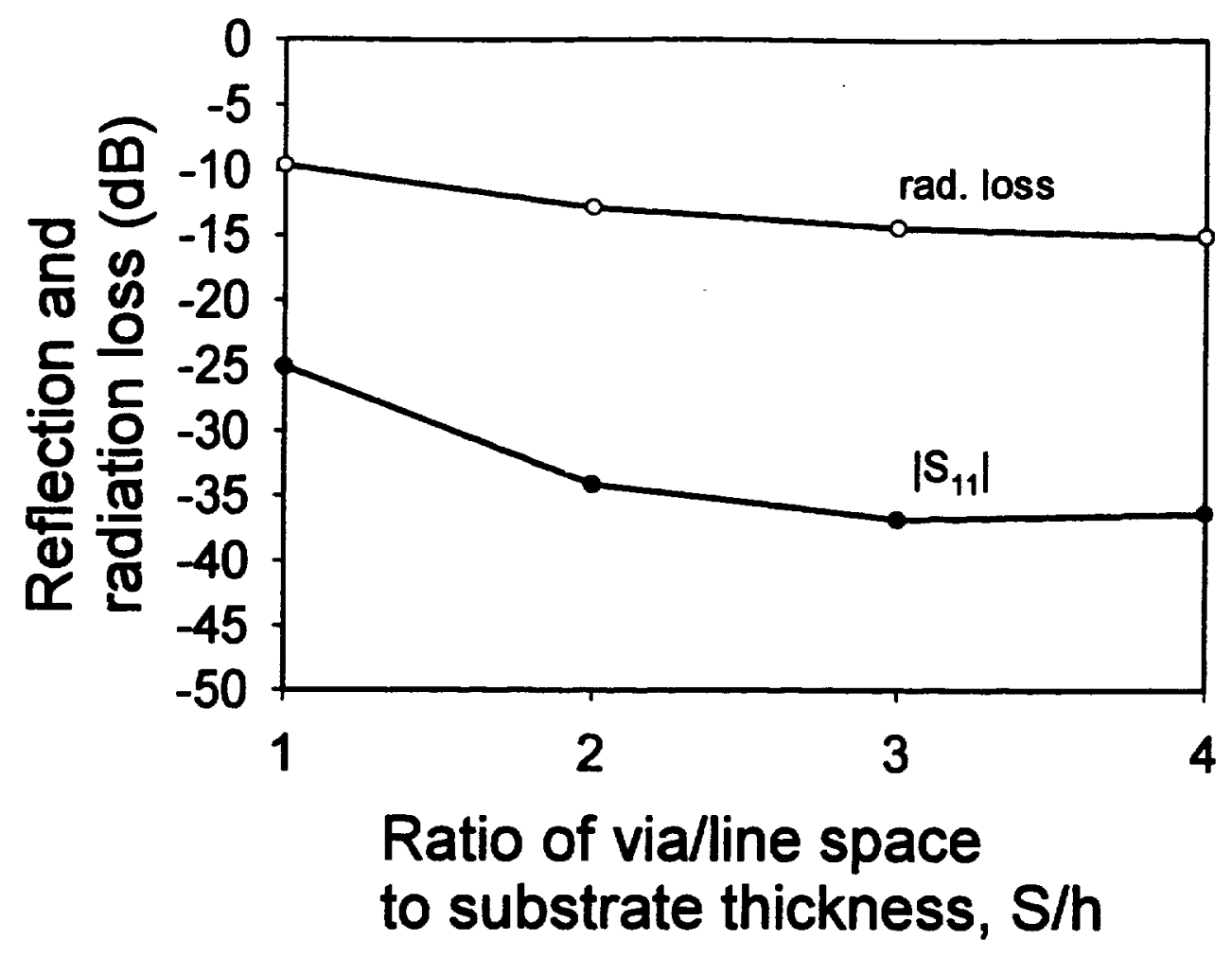

Fig $14 a$ 


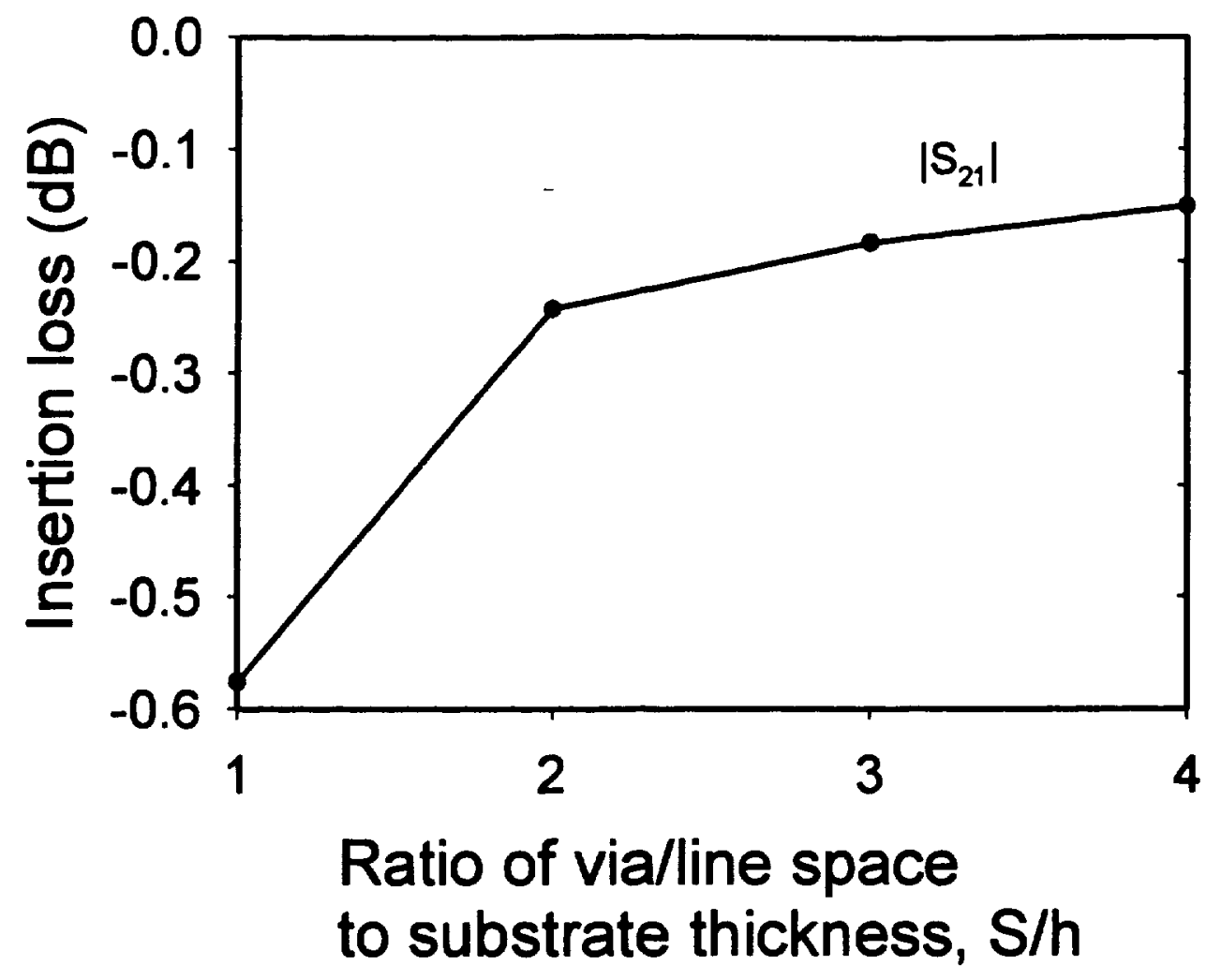

Fig 146 


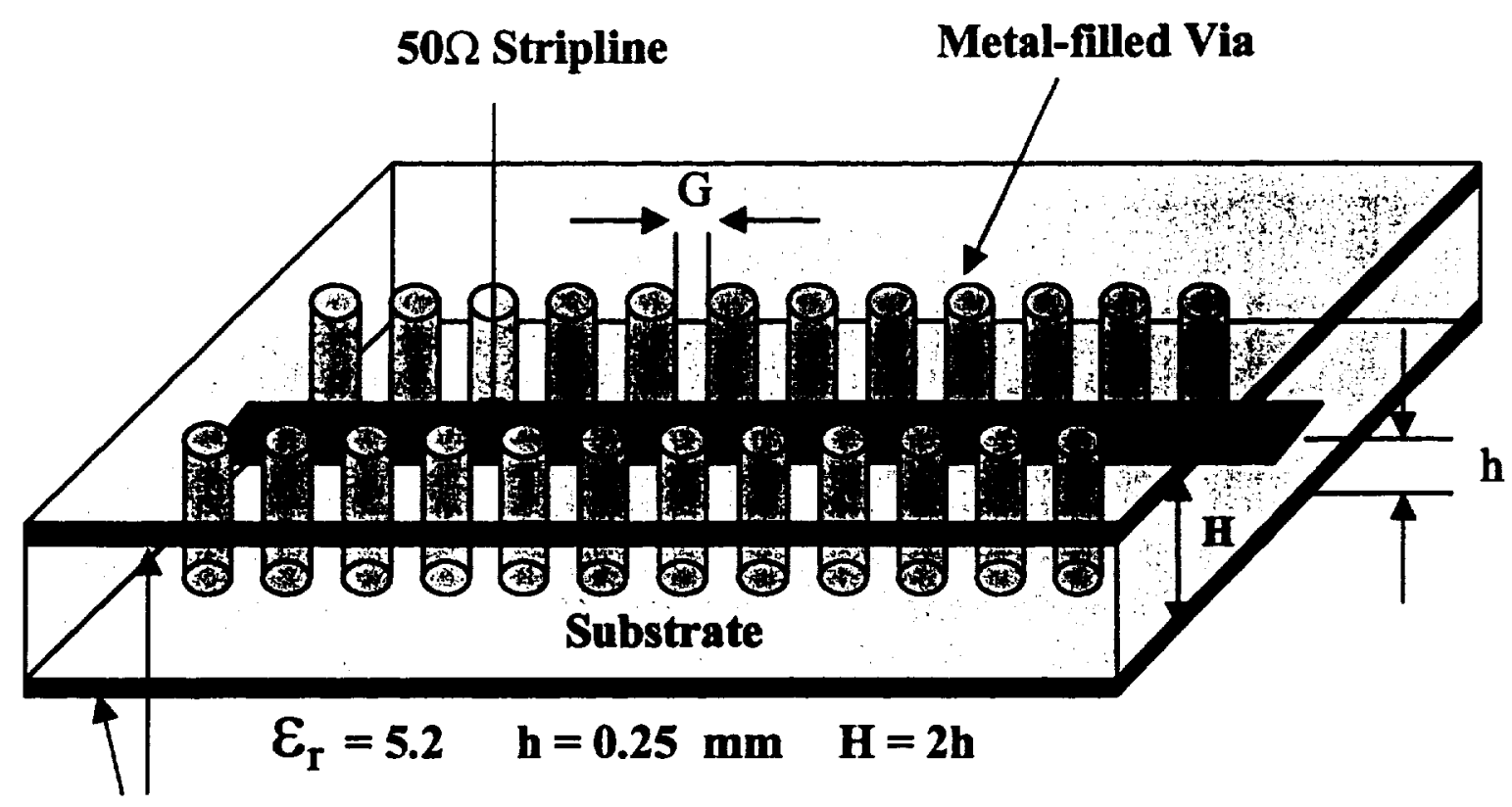

Ground Plane (Upper ground plane not shown for clarity)

Fig $15 a$ 


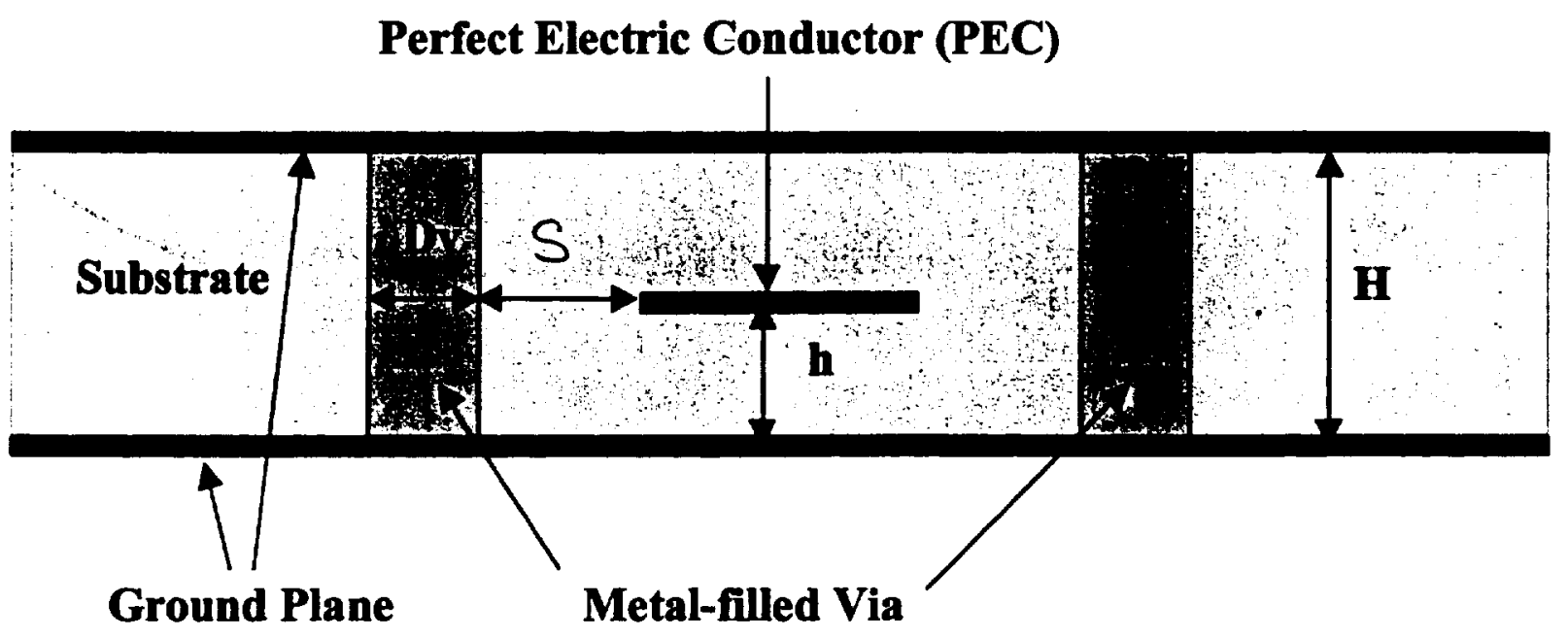

Fig $15 b$ 


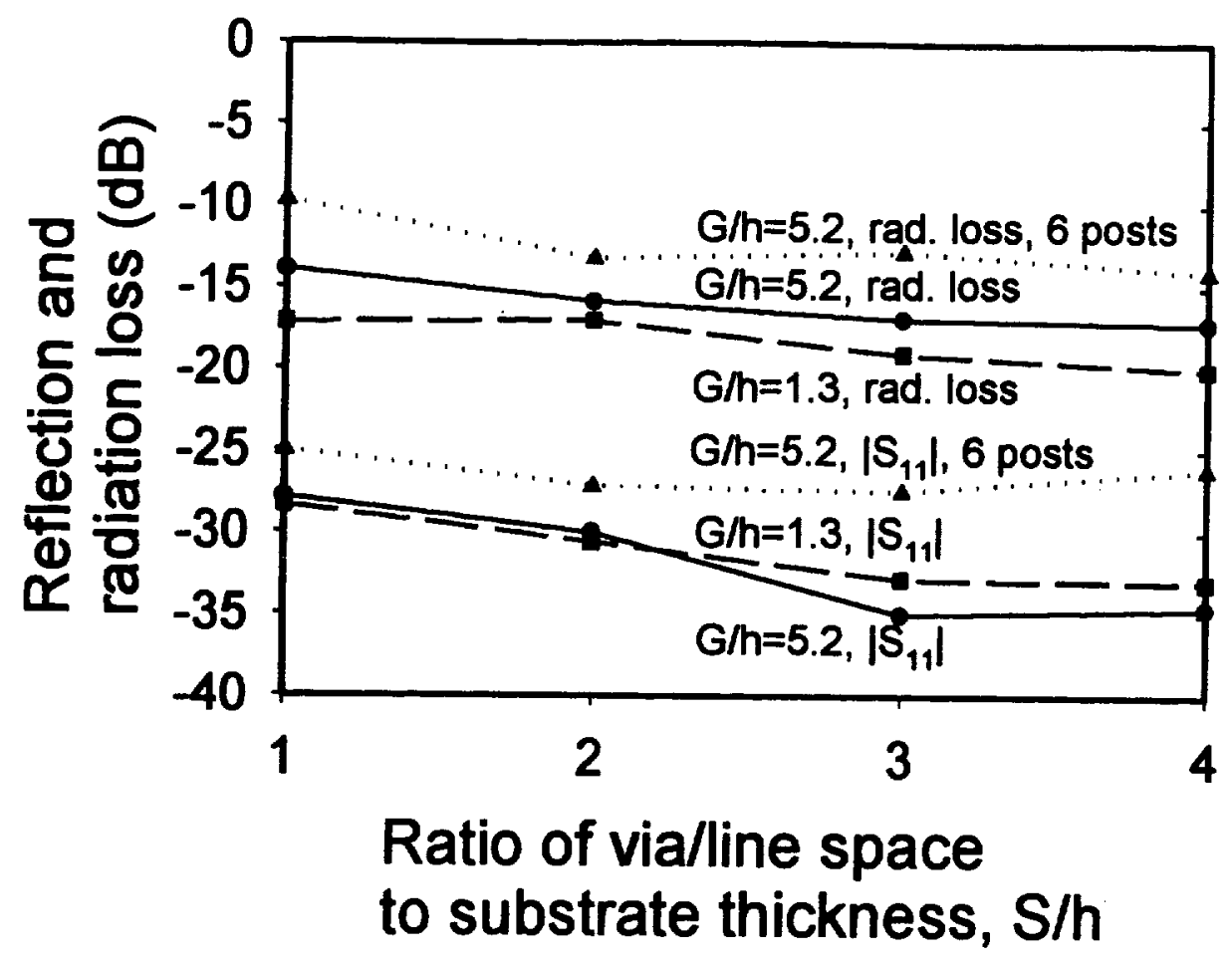

Fig $16 a$ 


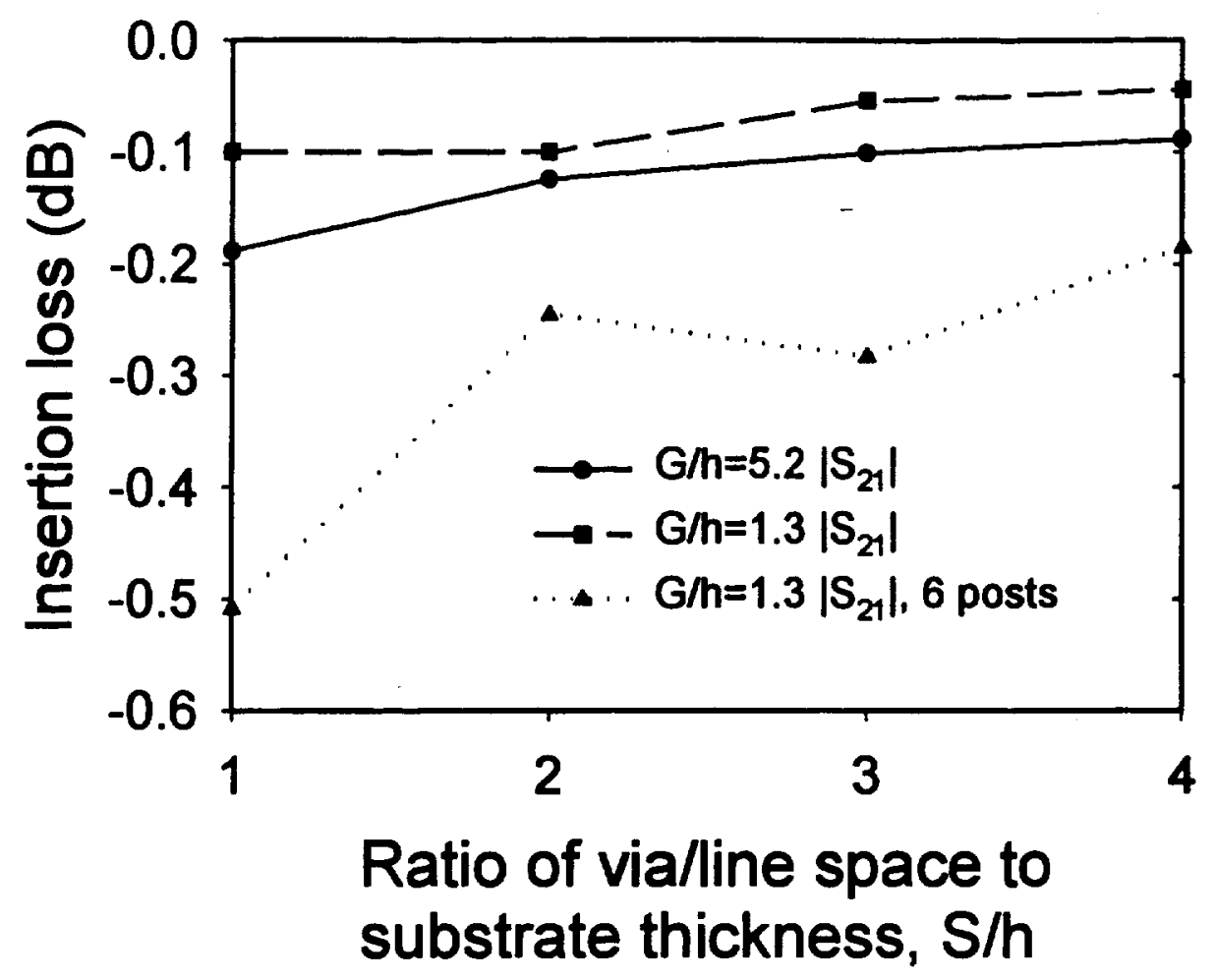

Fig 166 
$|\mathrm{E}|^{2}$, (dB)

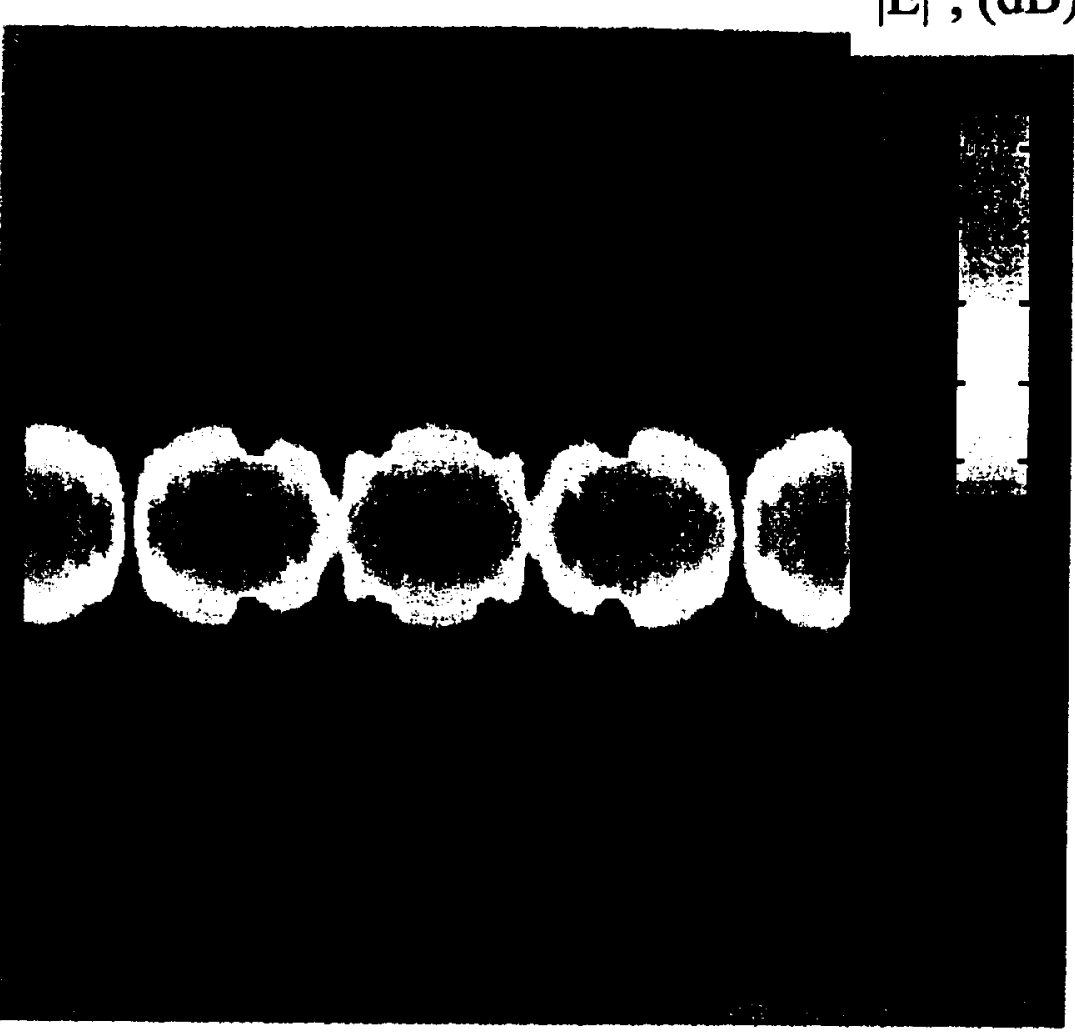

Fig $17 a$ 
$|\mathrm{E}|^{2}$, (dB)

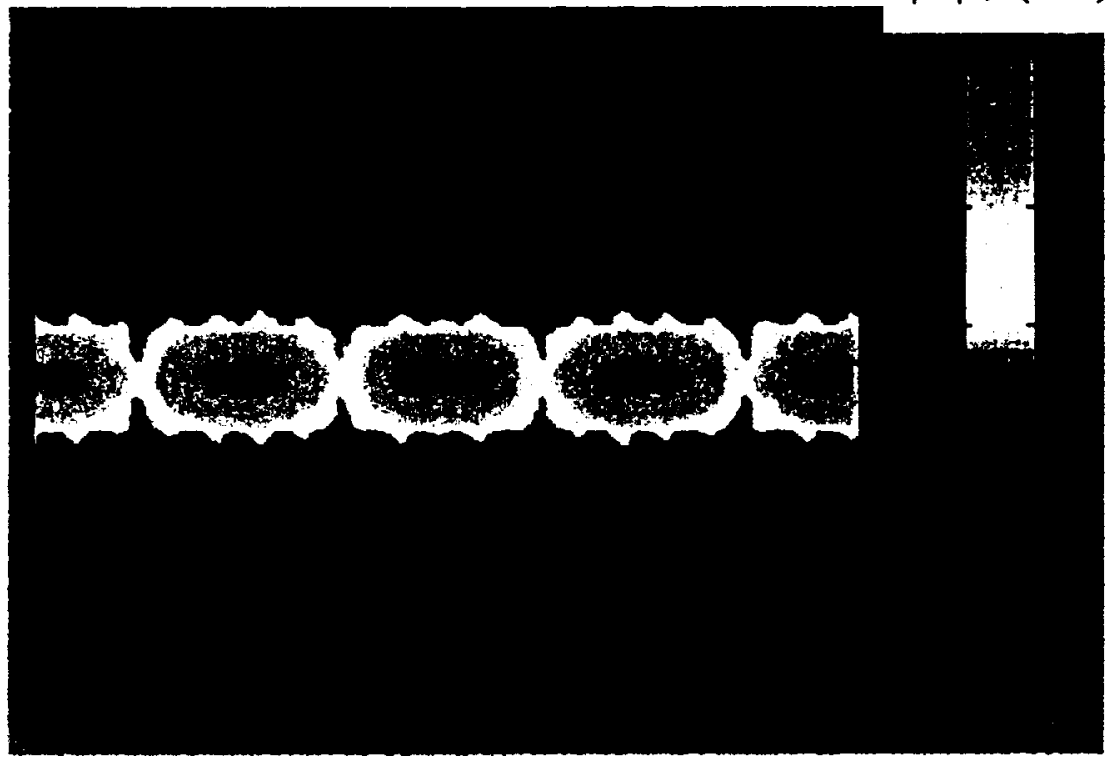

Fig 176 
$|\mathrm{E}|^{2}$, (dB)

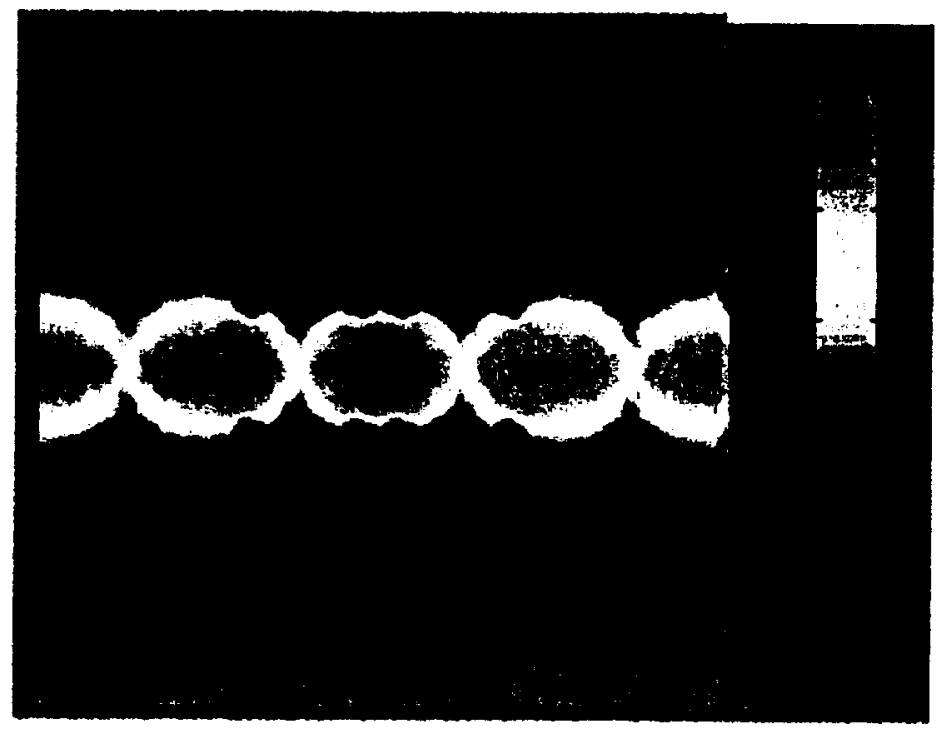

Fig 18 


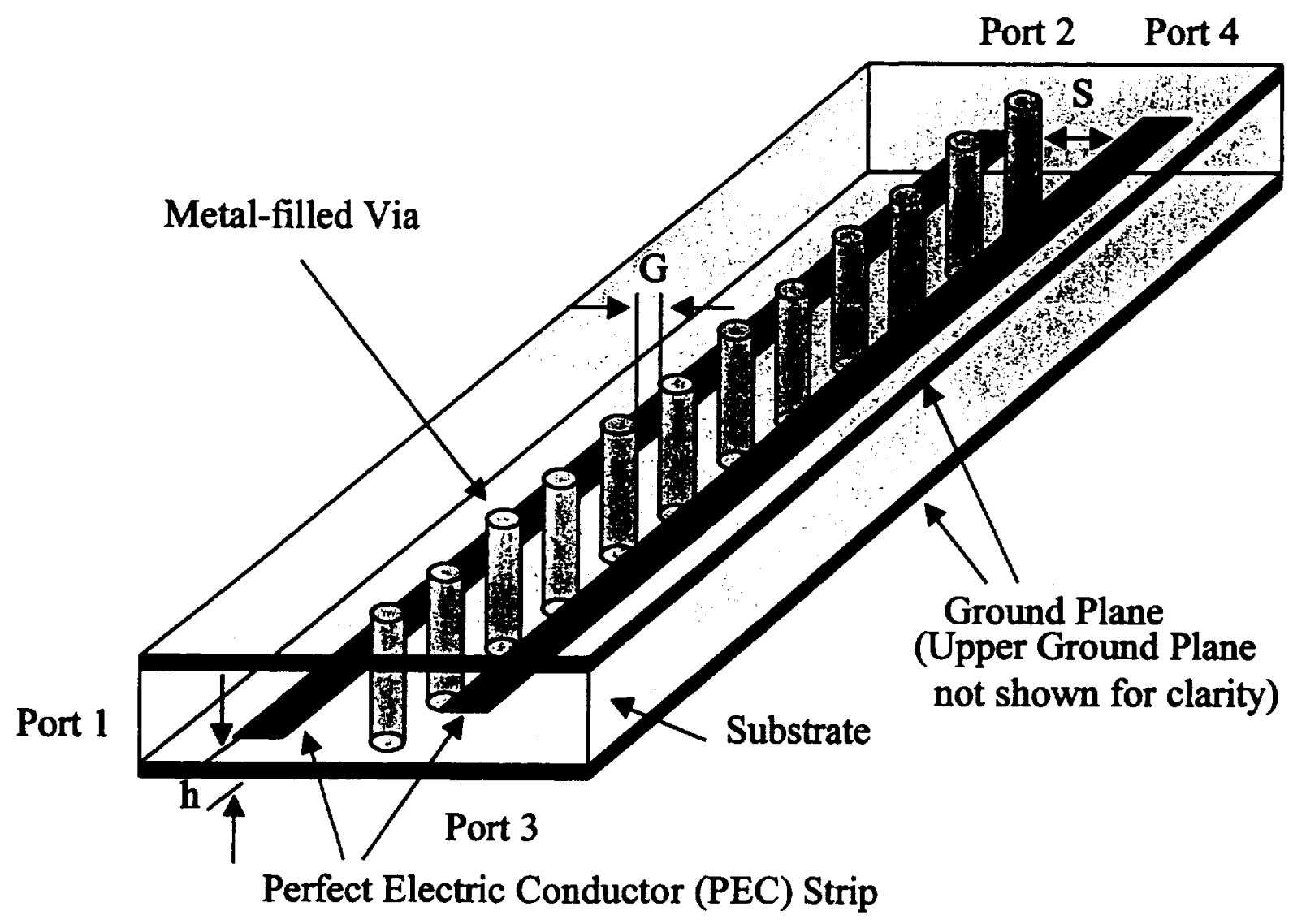

Fig 19 


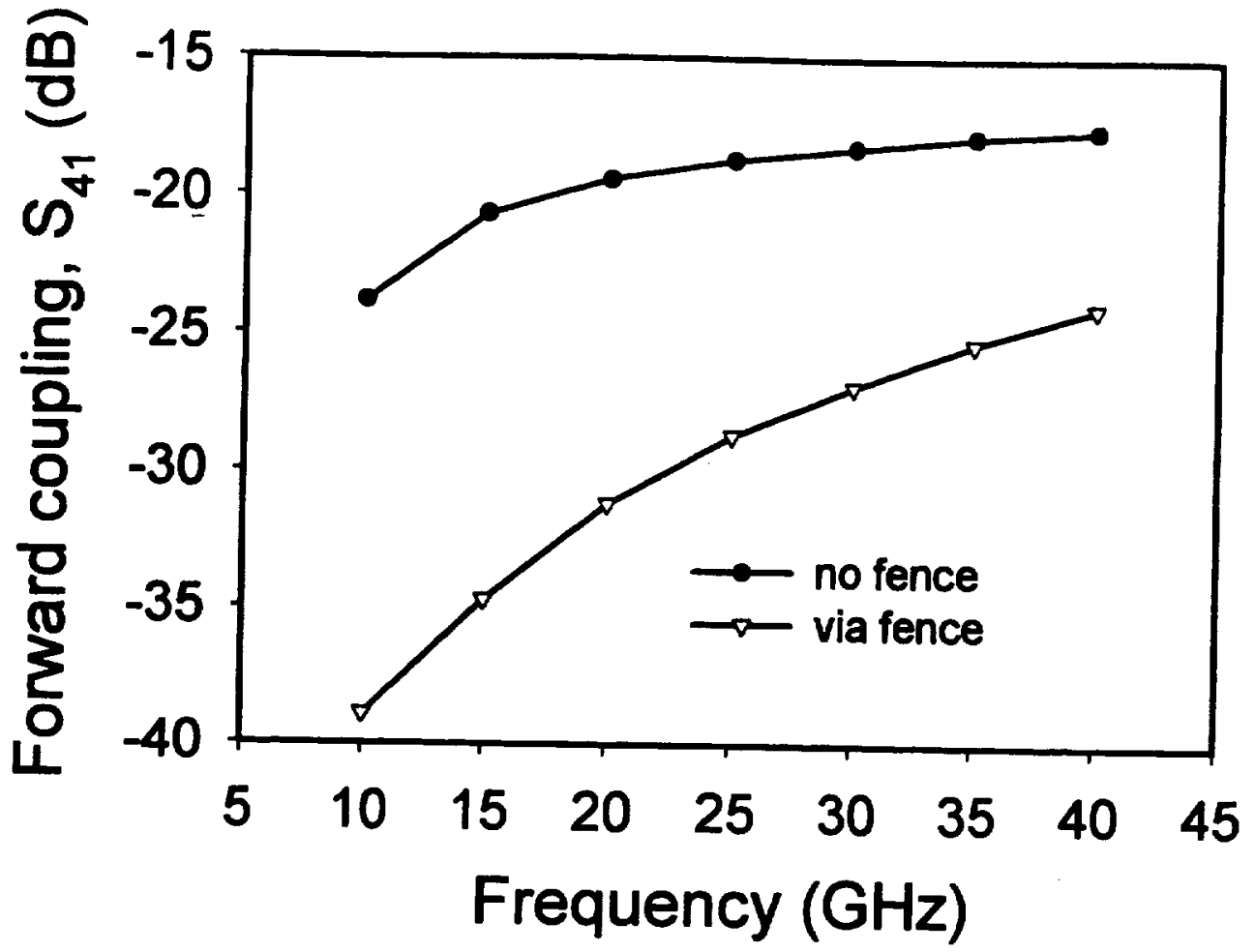

Fig 20 


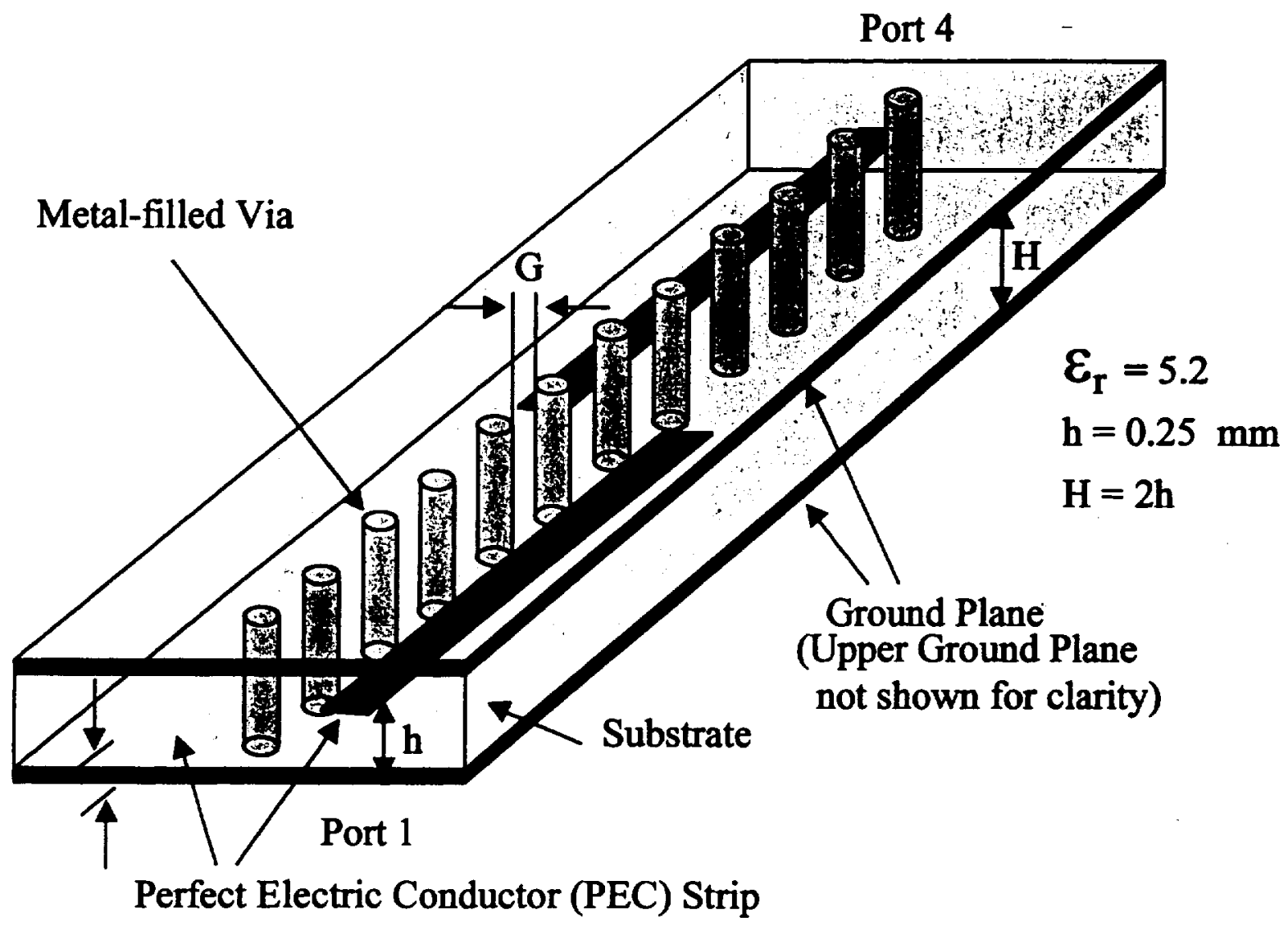

Fig z I 


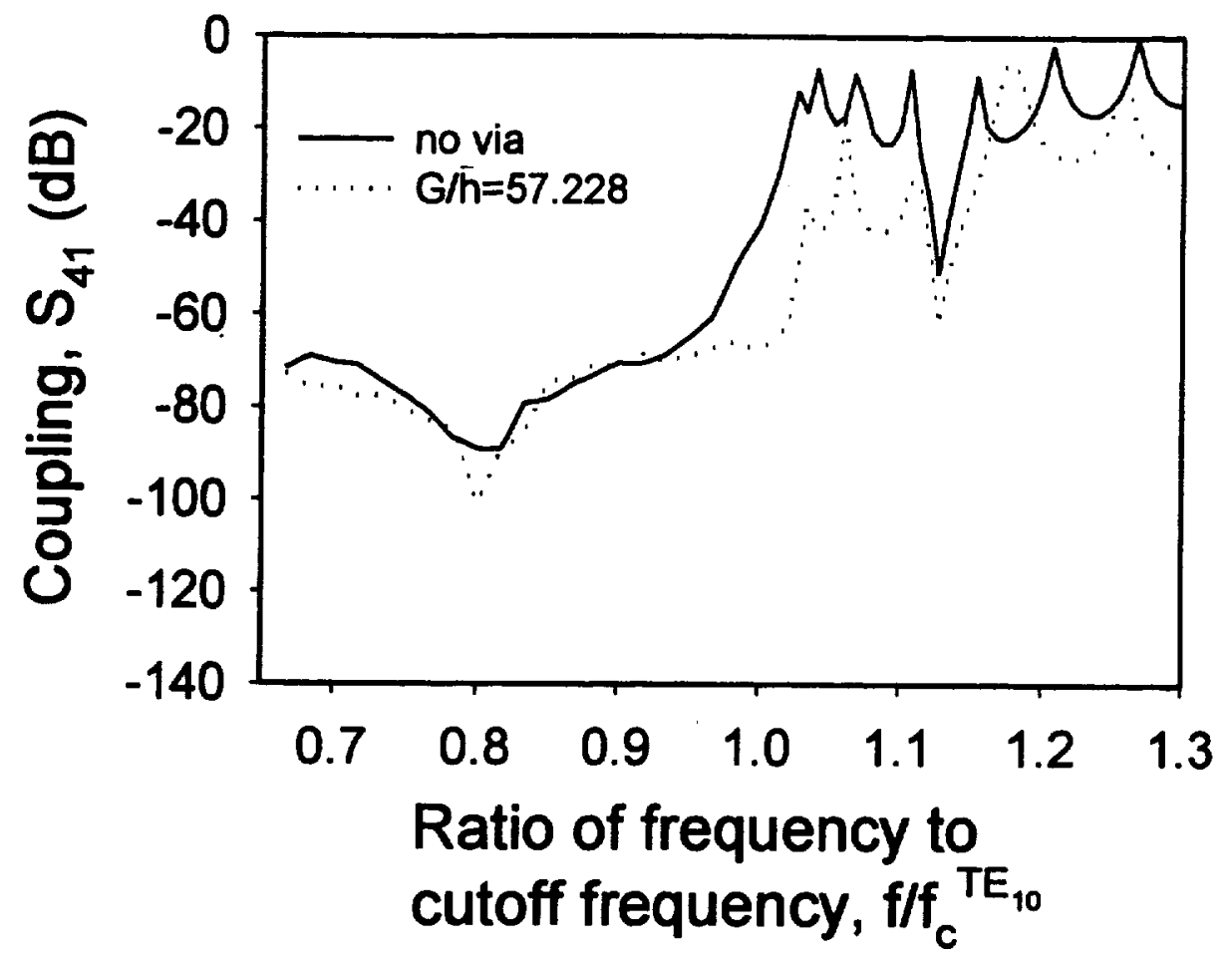

Fig $22 a$ 


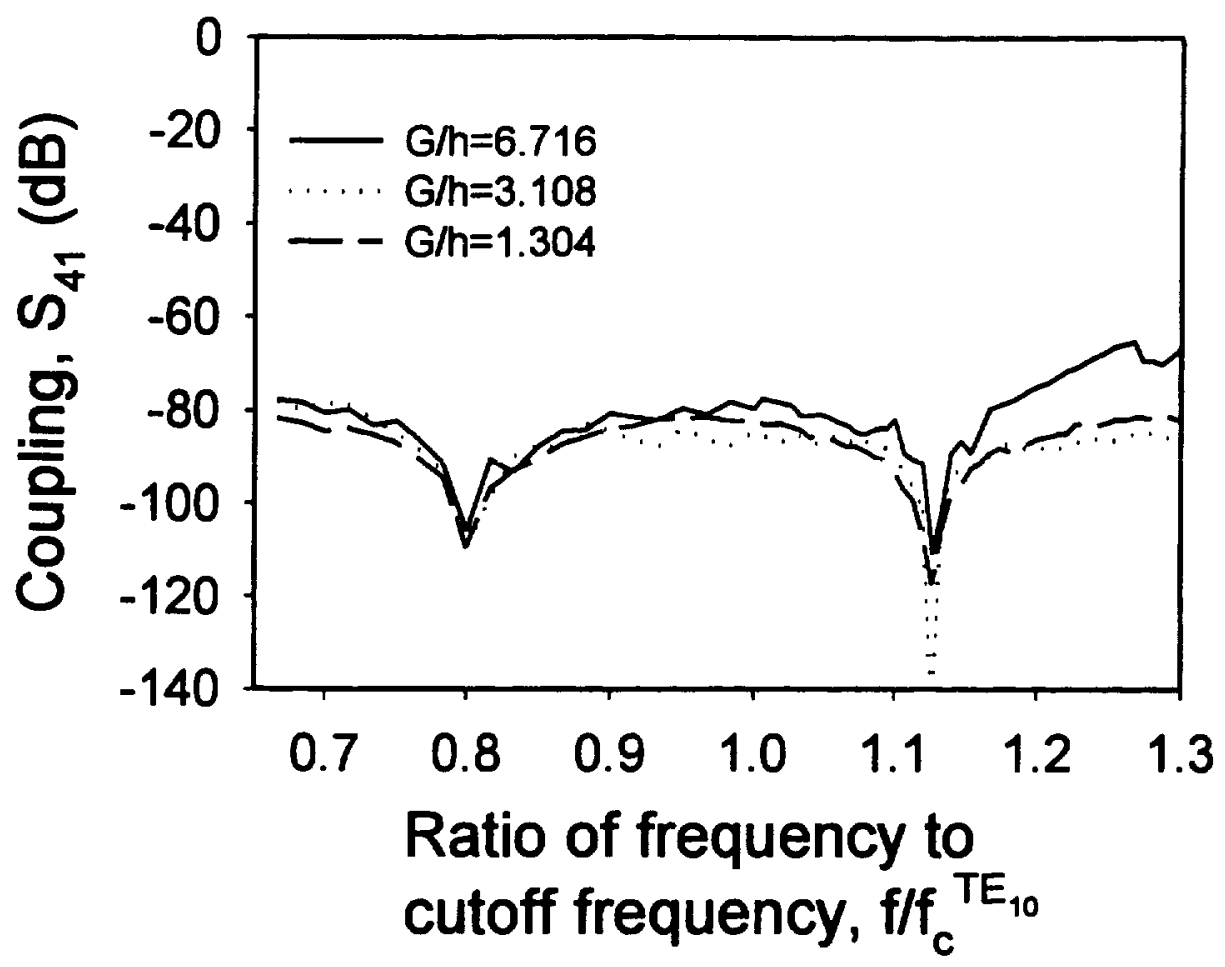

Fig $22 b$ 


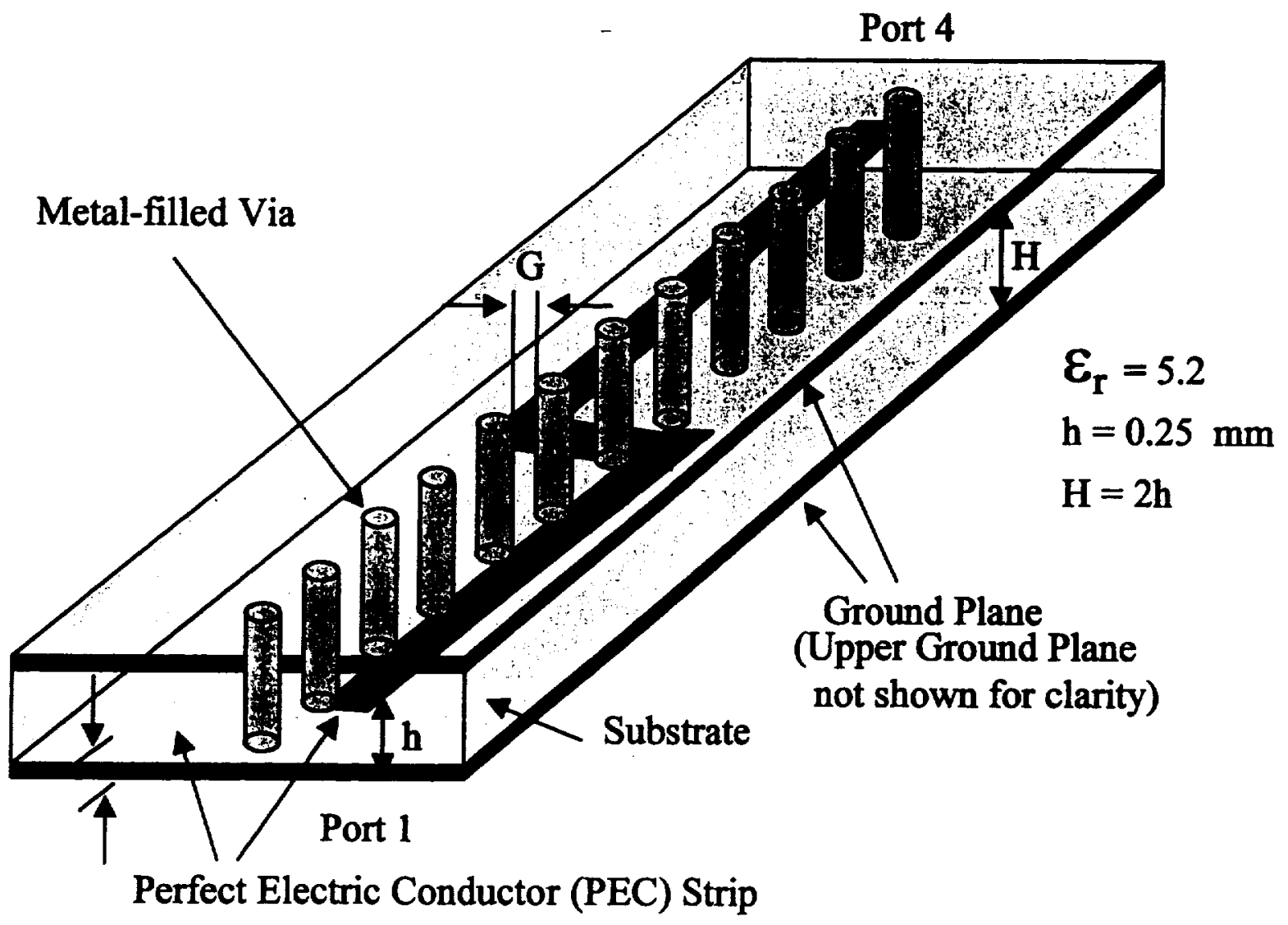

Fig 23 


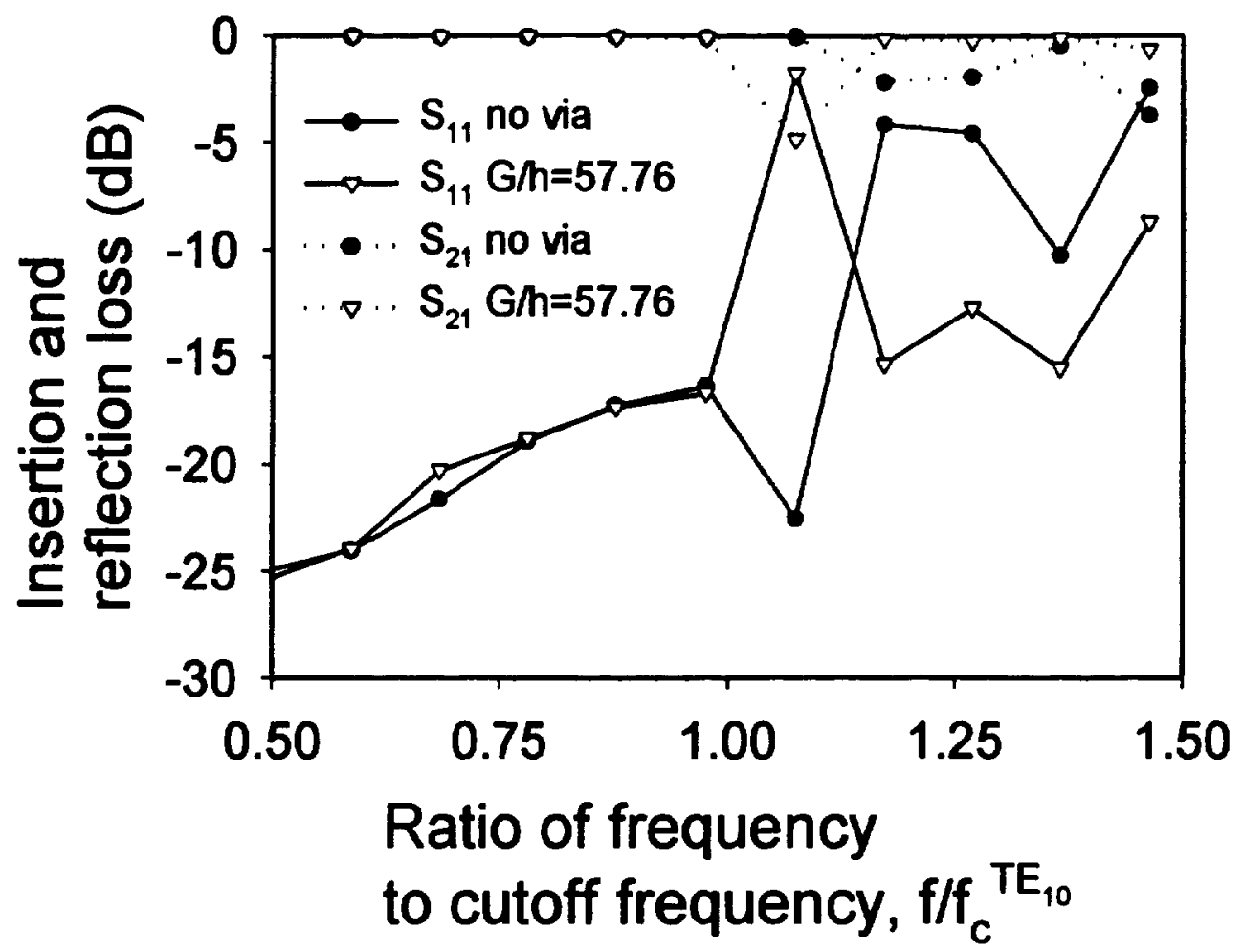

Fig $24 a$ 


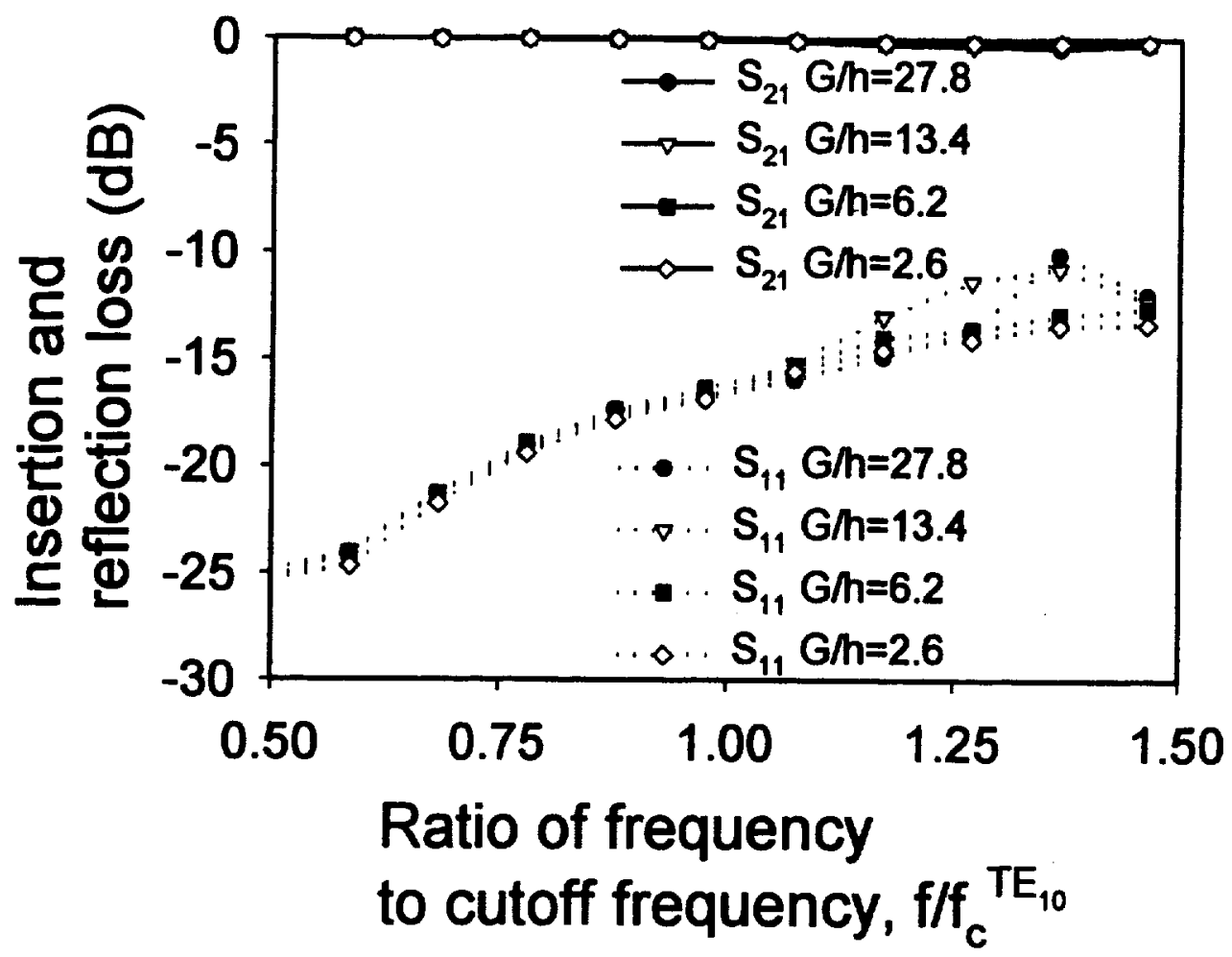

Fig $24 b$ 


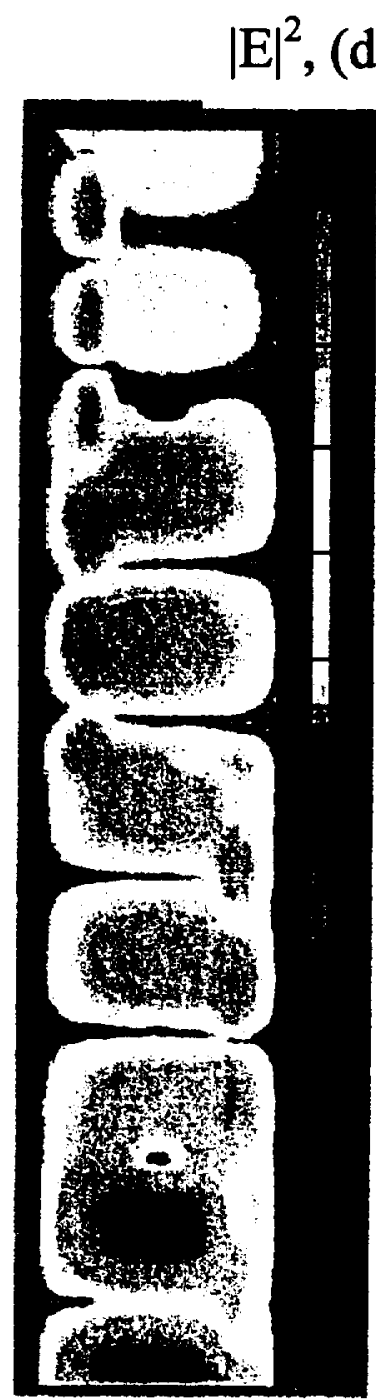

Fig $25 a$ 
$|E|^{2},(d B)$

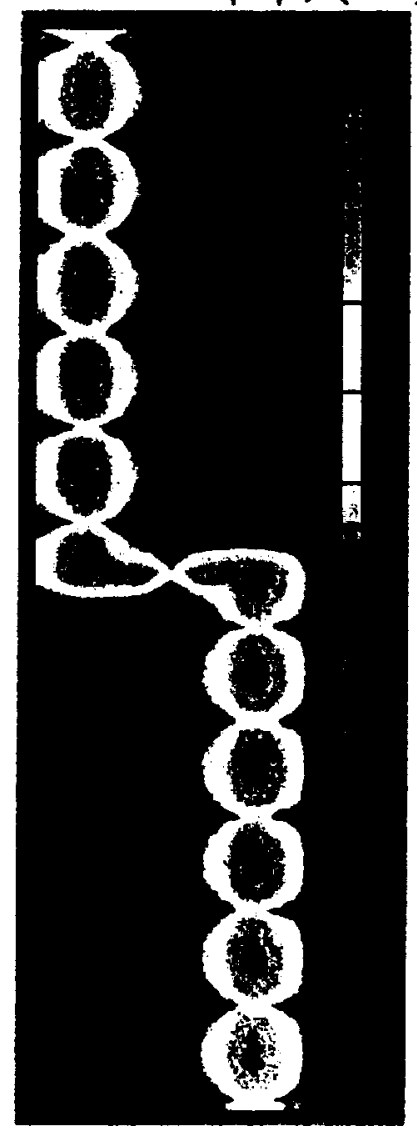

$\operatorname{Fig} 25 b$ 